\title{
NEOTECTÓNICA DE LA REGIÓN CENTRAL DE COSTA RICA: FRONTERA OESTE DE LA MICROPLACA DE PANAMÁ
}

\author{
Walter Montero \\ Escuela Centroamericana de Geología, Universidad de Costa Rica, \\ Apartado 214-2060 \\ E-mail:wmontero@geologia.ucr.ac.cr
}

(Recibido 9/2/2000; Aceptado 8/12/2000)

\begin{abstract}
Neotectonic, seismicity and seismotectonic data allow to define the Central Costa Rica Deformed Belt (CDCCR) as a wide and diffuse recent fault system located between the Caribbean plate and the Panama microplate, transverse to the central region of Costa Rica, and located between the Middle America Trench (Pacific side) and the North Panama Deformed Belt (Caribbean side). In the central pacific forearc, the fault system combines sinistral strike slip and normal slip. In the inner arc there is: 1) An external thrust fault system, with a predominantly WNW trend, and 2) An inner fault system including northwest dextral strike slip faults and east-northeast to northeast sinistral strike slip faults. In the backarc, the fault system joins the North Panama Deformed Belt, which shows an external northwest thrust and fold system and an inner northwest fault system combining dextral strike slip and reverse faulting.

The neotectonic faults which define the CDCCR are related to the collision of the Cocos Ridge with southern Costa Rica. The tectonic indentation caused by this collision produces the tectonic displacement to the east and north of the Panama microplate relative to the Caribbean Plate. This tectonic process produces normal slip combined with sinistral strike slip faulting in the western pacific rear side of the diffuse limit, causing the development of marine basins transverse to the forearc. On the other hand, in the leading side of the limit, an external thrust and fold system has been developed between the inner arc and the backarc. The predominantly strike slip faulting located inside the inner arc allows translational as well as rotational movements between the diverse tectonic blocks of the plate boundary zone.
\end{abstract}

RESUMEN: Datos neotectónicos, de sismicidad y de sismotectónica son usados para definir el Cinturón Deformado del Centro de Costa Rica (CDCCR) como un sistema de fallas reciente, difuso y ancho localizado entre la placa Caribe y la microplaca de Panamá, el cual es transversal a la región central de Costa Rica y localizado entre la fosa Mesoamericana (lado pacífico) y el Cinturón Deformado del Norte de Panamá (sector caribe). En el antearco pacífico central, el sistema de fallas combina desplazamientos de rumbo siniestral y normal. En el arco interno existe: 1) Un sistema externo de fallas inversas, que tiene rumbo predominante WNW en la región norte del país y 2) Un sistema interno de fallas que está constituído principalmente por fallas de desplazamiento de rumbo de tipos dextrales de dirección NW y siniestrales con rumbo entre ENE y NE. En la región trasarco, el sistema de fallas del CDCCR se une con el Cinturón Deformado del Norte de Panamá, el cual incluye un sistema externo de fallamiento inverso y plegamiento de rumbo noroeste y otro interno de desplazamiento de rumbo dextral combinado con desplazamiento inverso de rumbo noroeste.

Las fallas neotectónicas que constituyen el CDCCR son originadas por la colisión del levantamiento del Coco con el sur de Costa Rica. La indentación tectónica generada por esta colisión provoca el desplazamiento tectónico de la microplaca de Panamá con respecto a la placa Caribe, tanto hacia el sector este del Caribe como hacia el norte del país. Este proceso ha generado fallamiento extensional combinado con fallamiento transcurrente siniestral en la parte trasera oeste pacífica del límite difuso, lo que ha favorecido el desarrollo de cuencas marinas transversales al antearco. Por otro lado, el movimiento delantero de la microplaca de Panamá con respecto a la placa Caribe, ha originado un cinturón externo de fallas inversas y pliegues en la zona entre el arco interno y el trasarco. El sistema de fallas interno de desplazamiento de rumbo que está localizado dentro del arco interno permite movimientos traslacionales y rotacionales entre los diversos bloques tectónicos que constituyen la zona límite interplaca. 


\section{INTRODUCCIÓN}

Mediante la teoría de la tectónica de placas se puede describir en una forma bastante sencilla y elegante, los límites, la cinemática y las principales características tectónicas de la mayoría de las placas litosfericas. Sin embargo, en la región caribe de América se presentan varias placas y microplacas cuyas interacciones y fronteras son aún hoy día motivo de controversia. Para el Cuaternario existen diversos modelos para explicar los límites de la placa Caribe. Una de las regiones controversiales es la región de Costa $\mathrm{Ri}$ ca-Panamá, donde interaccionan las placas Coco, Caribe y Nazca y la recientemente propuesta microplaca de Panamá. Entre los modelos tectónicos que tratan de explicar la interacción entre las placas en esta zona, destacan los de Jordan (1975), Bowin (1976), Wolters (1986), Pennington (1981), Vergara (1988) y Adamek et al. (1988). Adamek et al. (1988) propusieron formalmente la existencia de la microplaca de Panamá, como un bloque tectónico ubicado entre las placas Nazca y Caribe. Diferentes propuestas existen con respecto al límite oeste de esta microplaca. Por ejemplo, Vergara (1988) lo ubicó transversal a la zona fronteriza de Panamá con Costa Rica. Otros autores consideran que este límite tectónico atravieza la región central de Costa Rica. Así, Montero \& Dewey (1982) consideraron la posible existencia de una zona de fallamiento siniestral uniendo la fosa Mesoamericana con el Cinturón Deformado del Norte de Panamá. Astorga et al. (1991) propusieron que Costa Rica se puede dividir en dos bloques: Costa Rica Norte y Costa Rica Sur y que la frontera entre ambos bloques es una zona de fallamiento siniestral transversal a la región central de Costa Rica, que denominaron la falla transcurrente de Costa Rica. A raíz de la actividad sísmica ocurrida en Costa Rica entre 1990 y 1993 y especialmente luego del terremoto de Limón del 22 de abril de $1991(\mathrm{Mw}=7,7)$, el cual tuvo epicentro en el borde caribe de la cordillera de Talamanca, se propuso que el borde oeste de la microplaca de Panamá, corresponde con una zona de cizalle siniestral, que atravieza transversalmente la región central de Costa Rica (Montero, 1990; Goes et al., 1993; Fan et al., 1993; Güendel \& Pacheco, 1992; Fisher et al., 1994; Montero, 1994a). En contraposición con los anteriores autores, Fernández (1996) y Fernández \& Pacheco (1998) no consideran que la sismicidad y sismotectónica del centro de Costa Rica apoyen el modelo anterior. En varios de los trabajos que concuerdan con el modelo, se usaron datos de sismicidad reciente y mecanismos focales. Un enfoque ligeramente diferente fue el de Fisher et al. (1994) y Montero (1994a) quienes sugirieron la existencia del borde oeste de la microplaca de Panamá a través de la región central de Costa Rica, a partir de fallas neotectónicas identificadas o sugeridas. Sin embargo, ninguno de los anteriores trabajos relacionó directamente el fallamiento activo con la sismicidad y con la sismotectónica, por lo que en este estudio se investiga y demuestra la correlación existente entre los anteriores tipos de datos con el modelo del límite oeste de la microplaca de Panamá.

\section{MARCO TECTÓNICO}

La placa del Coco se subduce bajo el margen pacífico de América Central, a partir de la fosa Mesoamericana (Fig. 1). Hacia el sureste, la zona de subducción termina en un punto triple. $\mathrm{Al}$ sur del mismo interaccionan la placa del Coco con la placa de Nazca, a lo largo del sistema de falla transformado dextral de Panamá, de rumbo N-S. Al este, la placa de Nazca se subduce en forma oblicua bajo el pacífico panameño. En Costa Rica, la subducción de la placa del Coco tiene diferentes características geométricas a lo largo de su rumbo (Protti et al., 1995a). Bajo el noroeste del país, se subduce corteza oceánica de batimetría suave, originándose una zona de Benioff con temblores de profundidad intermedia (150-200 km). Bajo la región central, ocurre la subducción de la frontera rugosa-suave, formada en el punto triple entre las placas Coco-Pacífica-Nazca. También, se subducen levantamientos oceánicos como el de Quepos (von Huene et al., 1995). Además, la zona de Benioff bajo el centro del país es menos profunda (hasta 100 km). Bajo el sur de Costa Rica, la subducción 


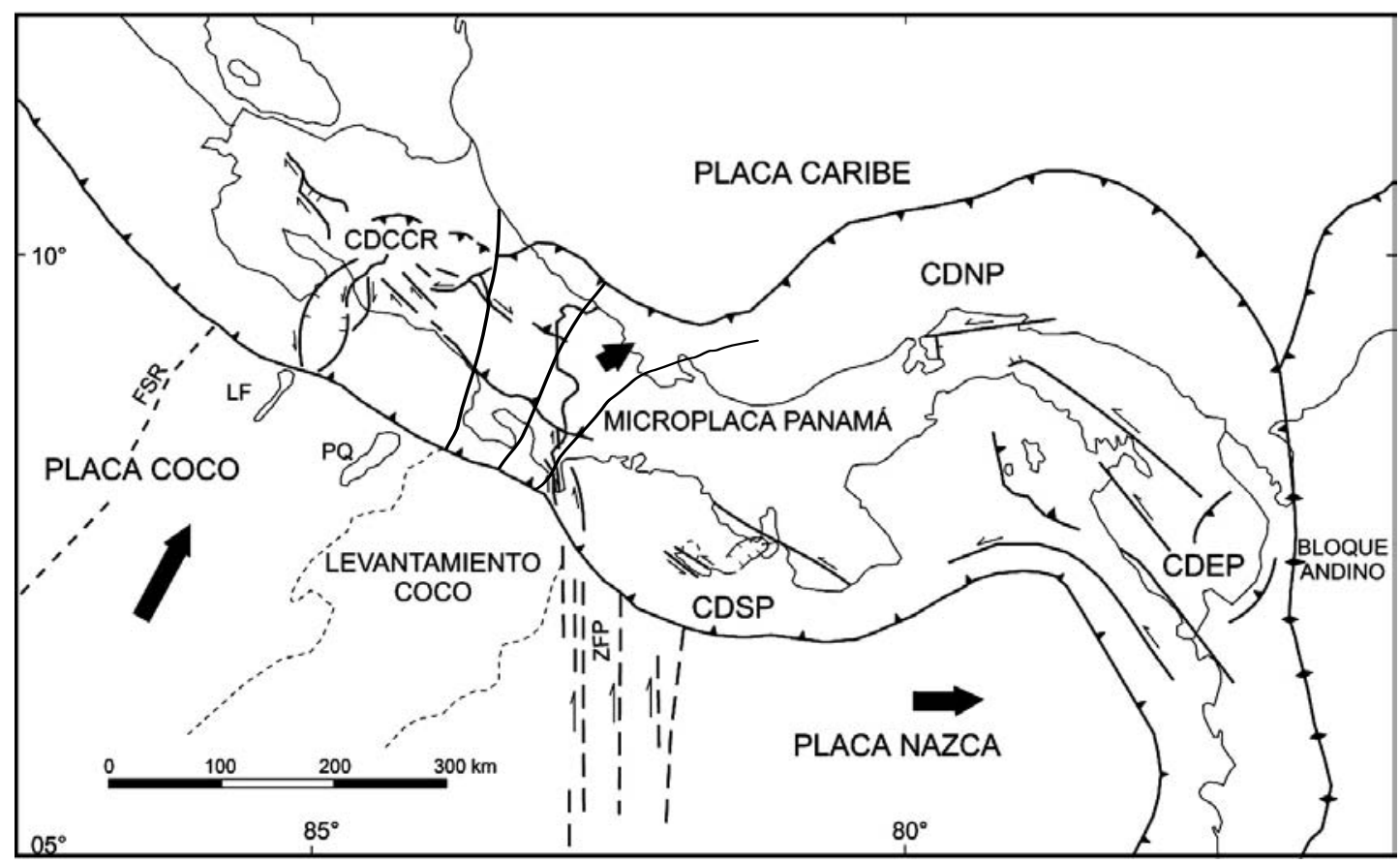

Fig. 1: Marco neotectónico del sur de Centro América, mostrando los límites de la microplaca de Panamá con las otras placas tectónicas. Las flechas rellenas indican las direcciones de los movimientos relativos de las respectivas placas con relación a la placa Caribe. Las lineas dentadas corresponden con fallas inversas, las lineas con una flecha al lado indican fallas de desplazamiento de rumbo con el movimiento relativo. Las fallas con líneas cortas son de desplazamiento normal del lado del bloque descendente. CDCCR, CDSP, CDNP y CDEP, son respectivamente los cinturones deformados del centro de Costa Rica y del sur, norte y este de Panamá. ZFP es la falla transformada de Panamá. FSR, LF y PQ son respectivamente la frontera suave-rugosa, el levantamiento de Fisher y el plateau de Quepos. Las líneas en forma de abanico muestran las direcciones esfuerzo principal máximo horizontal relacionadas con la indentación tectónica causada por el levantamiento del Coco (de acuerdo con Montero, 1994a).

del levantamiento oceánico del Coco, origina un proceso tectónico tipo colisión (Suárez et al., 1995). Montero (1994a), Kolarsky et al. (1995) y López (1999) propusieron que esta interacción ha originado la indentación del área continental central-sur del país, generando sistemas de fallas entre el Pacífico y el Caribe cuyos desplazamientos son controlados por la geometría del indentador y de la zona indentada.

La microplaca de Panamá limita al norte con la placa Caribe a lo largo del Cinturón Deformado del Norte de Panamá; al este con la placa suramericana, a lo largo del Cinturón Deformado del Este de Panamá (Mann \& Kolarsky, 1995); al sur con la placa Nazca, a lo largo de una zona con convergencia oblicua en su sector suroeste y de desplazamiento siniestral hacia el sureste. La ubicación del límite oeste de la microplaca de Panamá ha sido localizado en diferentes sectores entre el oeste de Panamá y Costa Rica. Como veremos, coincidimos con Montero (1990; 1994a), Goes et al. (1993), Fan et al. (1993), Güiendel \& Pacheco (1992) y Fisher et al. (1994), en considerar que dentro de la corteza continental del centro de Costa Rica, existe una zona de deformación de rumbo aproximado este-oeste, que incluye un complejo sistema de fallas activas de diversas geometrías, las cuales definen el límite incipiente oeste de la microplaca Panamá.

En este trabajo, se detalla esta zona de deformación, sus características estructurales y sismológicas y se plantea un modelo cinemático coherente, en el cual el movimiento relativo del bloque sur con respecto al norte, origina compresión a 
lo largo del centro del país, tanto en el sector norte de la cordillera volcánica Central como a lo largo del margen caribe, desde puerto Limón hacia el sureste, a lo largo del Cinturón Deformado del Norte de Panamá. Los desplazamientos horizontales anteriores resultan principalmente de movimientos en fallas predominantemente siniestrales, aunque otros tipo de fallas también contribuyen al proceso de interacción tectónico.

\section{DATOS Y MÉTODOS DE ANÁLISIS}

\section{Identificación y descripción del fallamiento Neotectónico}

Definimos las fallas neotectónicas como aquellas que sugieren o para las cuales ha sido determinado un desplazamiento cuaternario. El área de estudio se localiza entre las coordenadas $9^{\circ} 00^{\prime}$ y $10^{\circ} 30^{\prime} \mathrm{N}$ y $82^{\circ} 30^{\prime}$ y $85^{\circ} 00^{\prime} \mathrm{W}$. Las fallas del área continental han sido recopiladas de Alvarado et al. (1988), Alvarado (1989a), Woodward-Clyde (1993), Montero (1994a y b; 1999), Montero y Alvarado (1995) y Montero et al. (1998). Varias fallas neotectónicas incorporadas en este trabajo se detallan por primera vez. La mayoría de estas fallas fueron identificadas a partir del análisis geomórfico de fotografías aéreas y en menor medida en imágenes de radar o de Landsat. En un buen número de casos, las fallas neotectónicas han sido confirmadas por estudios de campo y sugeridas por la sismicidad y la sismotectónica. El detalle del estado del conocimiento que existe acerca de la mayoría de las fallas neotectónicas aquí estudiadas, se puede encontrar en Montero et al. (1998). En las figuras 2 y 3 se muestran las fallas del área continental que son analizadas en este estudio. Con respecto a la zona marina, se consideran las fallas incluídas en Barboza et al. (1995) y Fernández et al. (1997) (Fig. 4).

Las fallas se clasifican en dos tipos (Fig. 2). Las fallas neotectónicas, las cuales presentan una serie de elementos geomórficos prominentes que se pueden continuar claramente a lo largo de su extensión. Entre estos podemos mencionar escarpes, cambios de pendientes y valles lineales. Generalmente se reconocen por la presencia de varios elementos geomorfológicos distintos asociados. Normalmente han sido corroboradas en el campo y sugeridas por la sismicidad y la sismotectónica. En segundo término, están las fallas posiblemente neotectónicas, que se caracterizan por su expresión moderada a débil, y porque tienen elementos geomorfológicos lineales que se pueden continuar, pero tienen una naturaleza discontinua.

\section{Sismicidad y sismotectónica}

La sismicidad se ha obtenido de la base de datos de la Red Sismológica Nacional (RSN, integrada por el Instituto Costarricense de Electricidad, ICE y la Universidad de Costa Rica, UCR). Incluye los sismos ocurridos entre abril de 1984 y 1998 (Fig. 5). Los temblores tienen magnitudes $\geq 3,5$ y profundidades $\leq 20 \mathrm{~km}$.

El análisis sismotectónico se realizó recopilando y seleccionando mecanismos focales de sismos corticales (profundidades $\leq 25 \mathrm{~km}$ ) y de magnitudes $\geq 4,0$, del período 1924-1998. También, se han realizado ocho mecanismos focales de sismos corticales de magnitudes $\geq 4,0$ ocurridos entre 1987 y 1998 para los cuales existen suficientes datos de primeros arribos de onda P. Los parámetros focales y las respectivas soluciones de los eventos seleccionados se tienen a disposición de los interesados que así lo soliciten. Los mecanismos focales se muestran en las figuras 2 y 3 y se numeran de acuerdo al orden cronológico de su ocurrencia. Los criterios de calidad son los mismos utilizados por Fernández (1995), pero se incluyen además mecanismos focales obtenidos por el modelaje de formas de onda, los cuales son de calidad A si los planos nodales están bien restringidos y de calidad B si existe algún plano nodal regular o mal restringido.

Existen otros estudios donde se analizan secuencias sísmicas ocurridas dentro del área de estudio, que incluyen mecanismos focales individuales para temblores de magnitudes $<4,0$ o compuestos para eventos de diferentes magnitudes, que no hemos incorporado en las figuras 2 y 3 , que en algunos casos serán discutidos. 


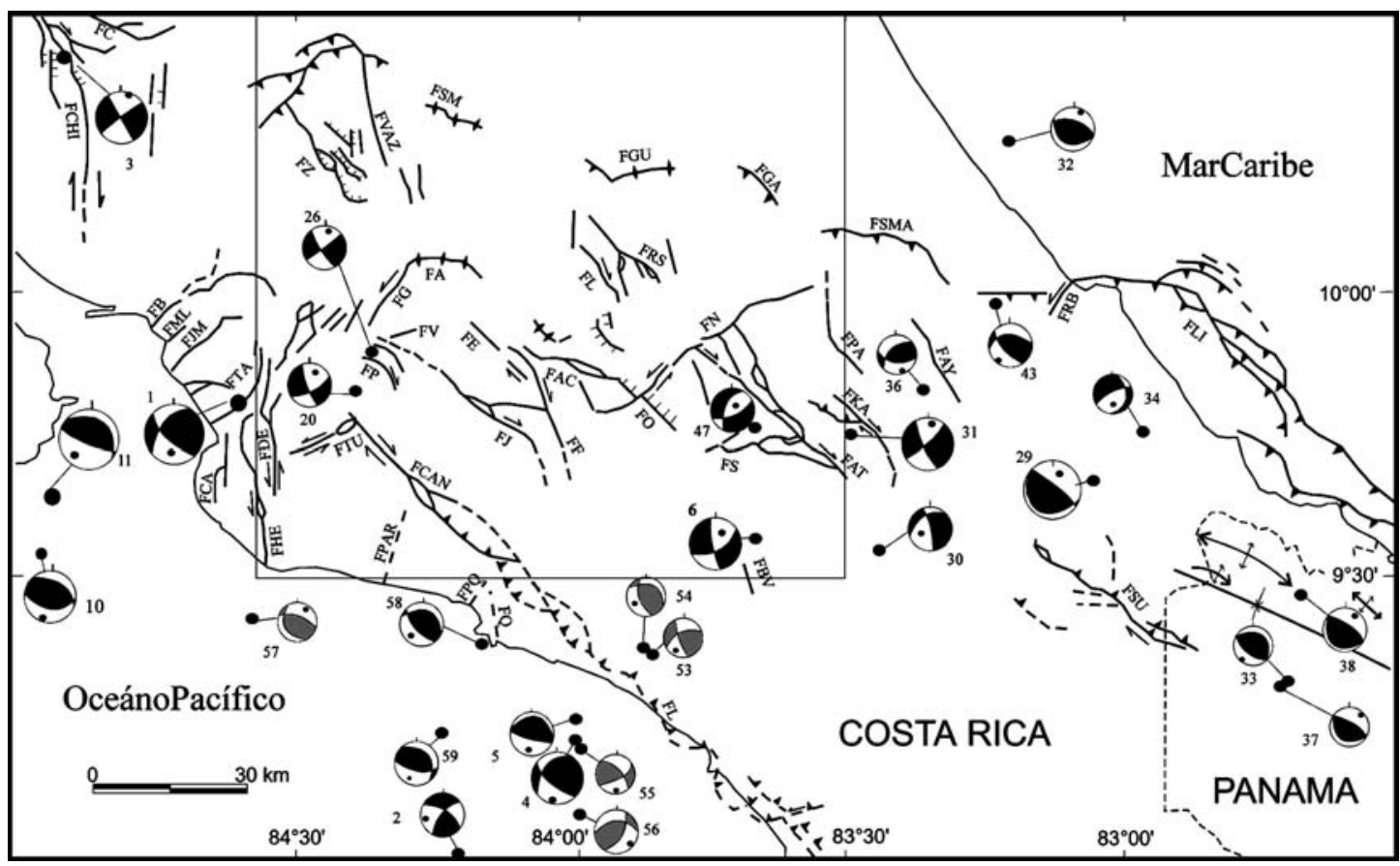

Fig. 2: Fallas neotectónicas que definen el Cinturón Deformado del Centro de Costa Rica. Simbología para fallas de acuerdo a la figura 1. Las lineas continuas se interpretan como fallas neotectónicas y las que están a trazos son fallas posiblemente neotectónicas. Fallas región antearco: Barranca (FB), Mata de Limón (FML), Jesús María (FJM), Tárcoles (FTA), Camaronal (FCA), Delicias (FDE), Herradura (FHE), Parrita (FPAR), Paquita (FPQ), Quepos (FQ) y Tulín (FTU). FCAN y FL son las fallas Candelaria y Longitudinal que separan la región antearco del arco interno. Arco interno: Cote-Arenal (FC) y Chiripa (FCHI), Zarcero (FZ), Viejo-Aguas Zarcas (FVAZ), San Miguel (FSM), Alajuela (FA), Guápiles (FGU), Lara (FL), Río Sucio (FRS), Guácimo (FGA), Garita (FG), Picagres (FP), Virilla (FV), Escazú (FE), Agua caliente (FAC), Jaris (FJ), Frailes (FF), Navarro (FN), Orosi (FO), Atirro (FAT), Simari (FS), Kabébeta (FKA), Pacuare (FPA), Ayil (FAY), Siquirres-Matina (FSMA), Río Blanco (FRB), Buena Vista (FBV) y Sukut (FSU). Mar Caribe: falla Limón (FLI). Se incluyen los epicentros y los mecanismos focales de temblores de magnitudes $\geq 5,0$, numerados de acuerdo con la tabla que se puede pedir al autor. Los tamaños de los epicentros y mecanismos focales corresponden a las siguientes clases de magnitud de los sismos: 5,0 $\leq \mathrm{M} \leq 5,9,6,0 \leq \mathrm{M} \leq 6,9$ y $\mathrm{M} \geq 7,0$. Los cuadrantes rellenos son zonas de compresión y en blanco las de dilatación. El punto dentro del mecanismo indica la posición del eje de presión. Las zonas compresivas de los mecanismos focales se muestran en negro si son de calidad A, en gris de calidad B y en gris claro si son de calidad C. En el recuadro se define el área cubierta por la figura 3 .

\section{NEOTECTÓNICA, SISMICIDAD Y SIS- MOTECTÓNICA DE LA REGIÓN CENTRAL DE COSTA RICA}

\section{ANTEARCO CENTRAL}

En el antearco pacífico central existe un sistema de fallas de rumbo NE a N, el cual parece iniciarse en el sector oceánico y continuarse en la zona continental. Incluye las fallas Barranca, Jesús María, Tárcoles, Bijagual, Parrita, Paquita, Quepos y Tulin y se ha propuesto que estas tienen desplazamiento entre normal y normal sinistral (Madrigal, 1970; Fischer, 1980; Fisher et al., 1994, 1998; Montero, 1994a, 1999; Barboza et al., 1995; Fernández et al., 1997; ver figuras 2, 3 y 4). Algunas de estas fallas limitan un sistema de bloques que tienen basculamiento normalmente hacia abajo en su lado noroeste (Fisher et al., 1994, 1998). En el sector sureste de la península de Nicoya, un basculamiento similar se encuentra en la superficie de Cóbano (Fisher et al., 1998).

Madrigal (1970) fue el primero en cartografiar este sistema de fallas transversal a la costa, llamándole la atención el rejuvenecimiento 


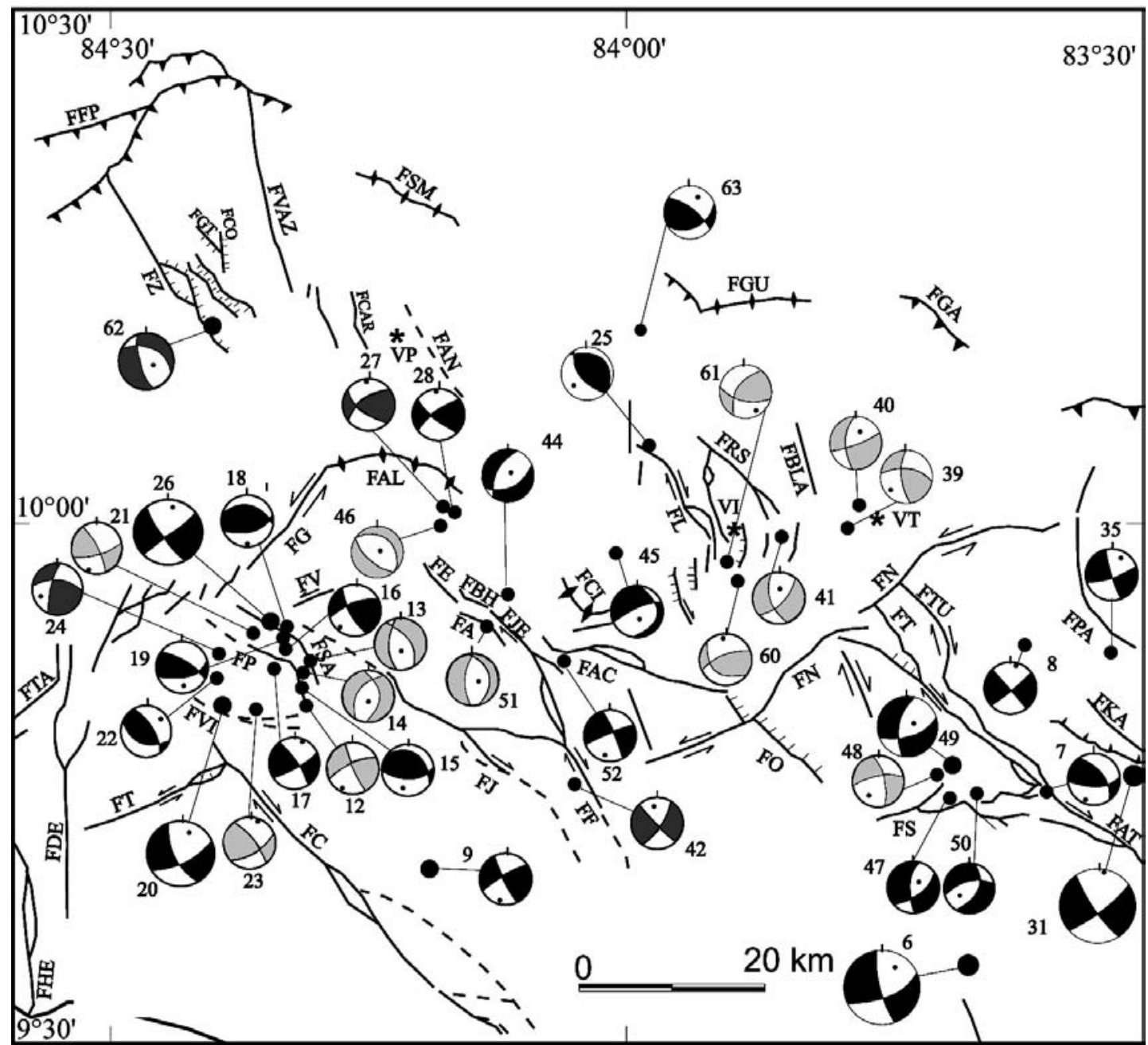

Fig. 3: Sismotectónica y neotectónica de la región central de arco interno de Costa Rica. La simbología es de acuerdo a lo definido en las figuras 1 y 2 . Se incluyen todos los mecanismos focales de los temblores de $\mathrm{M} \geq 4,0$, excepto en la zona de Puriscal donde solo se muestran aquellos de $M \geq 4,5$. Además, se muestran las fallas Víbora (FVI), San Antonio (FSA), Belo Horizonte (FBH), Jericó (FJE), Cipreses (FCI), Florencia- La Palmera (FFP), Gata (FGT), Congo (FCO), Carbonera (FCAR), Angel (FAN), Blanco (FBLA), Tucurrique (FT) y Turrialba (FTU). Se indican los volcanes Poás (VP), Irazú (VI) y Turrialba (VT).

general de la región de Esparza-Orotina (según lo evidencia la gran profundidad de los valles principales con respecto al nivel del mar). Fischer (1980), con base en superficies bioerosionales, reconoció una serie de zonas de levantamiento y hundimiento a lo largo de la costa, que se pueden relacionar con las fallas Barranca, Jesús María, Tárcoles y el sistema de Bijagual. Corrigan et al. (1990) propusieron la existencia de una falla en la entrada del Golfo de Nicoya, de rumbo NE y transversal a la costa, que denominaron falla del
Este de Nicoya, que desplazaría una cuenca en sentido siniestral y que relacionaron con la indentación del levantamiento del Coco. La posición de esta falla es similar a la falla propuesta por Fernández et al. (1997), inmediatamente al este de la península de Nicoya y que podría ser la extensión de la falla Barranca en el área marina. Fisher et al. (1994) y Montero (1994a; 1999) consideran que este sistema de fallas limita la microplaca de Panamá con respecto a la placa Caribe, mientras que Fisher et al. (1998) consideran que la ubicación y 


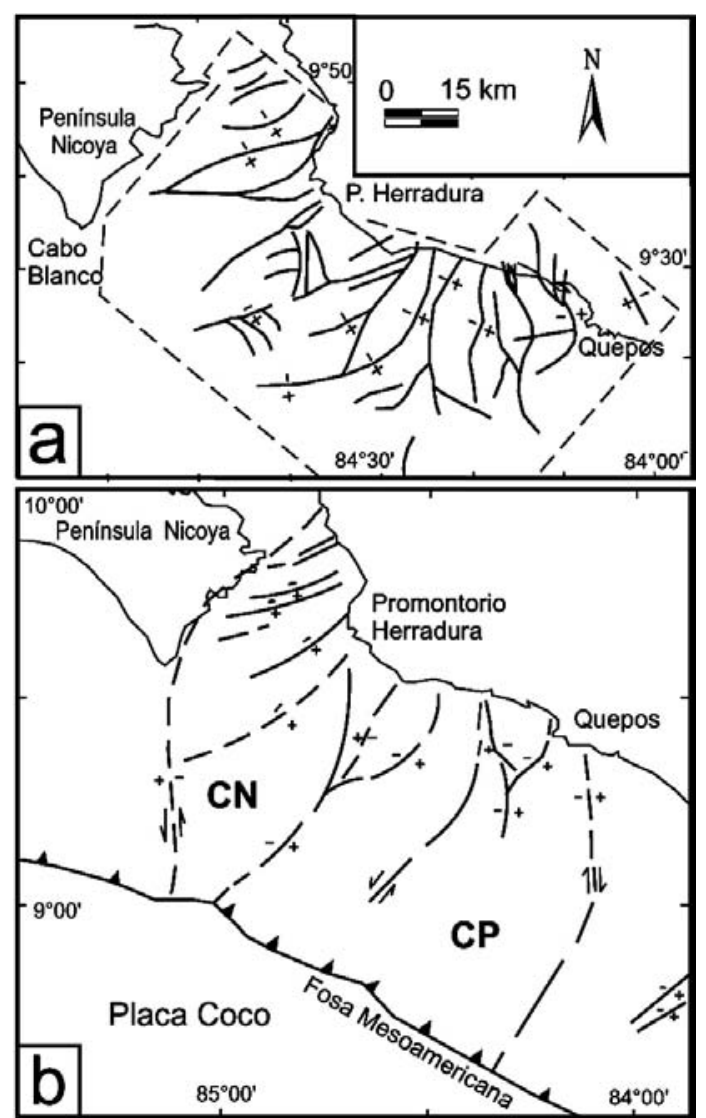

Fig. 4: a) Sistema de fallamiento neógeno a la entrada del golfo de Nicoya de acuerdo con Barboza et al. (1995). Algunas de estas fallas pueden ser cuaternarias de acuerdo con los anteriores autores. b) Sistema de fallas de la entrada del golfo de Nicoya de acuerdo con Fernández et al. (1997). CN y CP son las cuencas Nicoya y Parrita, respectivamente.

movimiento de estas fallas lo controla la subducción de los montes submarinos de rumbo NE, que son acarreados por la placa del Coco (von Huene et al., 1995).

Una descripción más detallada de la mayoría de las anteriores fallas se encuentra en Montero (1999). El sistema de fallas de Bijagual se divide aquí en las fallas Camaronal, Herradura y Delicias. Además, denominamos con los nombres de fallas Parrita, Paquita y Quepos a las fallas que limitan el sector oriental del bloque Esterillos y el occidental y oriental del bloque Quepos, según fueron definidos por Fisher et al. (1998). Estas fallas parecen iniciarse en el área marina (Barboza et al.,1995; Fernández et al.,1997). En el área continental, la falla Parrita se ubica de acuerdo con Sak et al. (1997) y las fallas Paquita y Quepos limitan el promontorio de Quepos (Baumgartner \& Mora, 1984).

En la zona marina de la entrada del golfo de Nicoya y de los promontorios de Herradura y Quepos, las fallas que desplazan las cuencas de Nicoya y Parrita son predominantemente normales, aunque algunas tienen también una componente de rumbo (Barboza et al., 1995; ver Fig. 4a). Estos autores indican que las fallas afectan los depósitos pliocénicos y sugieren que las mismas pueden alcanzar a desplazar los sedimentos cuaternarios. Fernández et al. (1997), partiendo de los resultados de Barboza et al. (1995), proponen la existencia de un sistema marino de fallas transtensionales que se continúa en el área continental (Fig. 4b). Se considera que las fallas mostradas por Barboza et al. (1995) son bastante confiables, considerando que han sido obtenidas de la interpretación de perfiles de reflexión sísmica.

El estudio de las réplicas del terremoto de Cóbano del 30 de marzo de $1990(\mathrm{Mw}=7,0$; evento 11 en figura 2), muestra que estas ocurrieron tanto en la zona interplaca como dentro de la corteza cabalgante a la placa del Coco. Protti et al. (1995b), al definir el área de ruptura de este terremoto, muestran un alineamiento de temblores de rumbo noreste que va desde la punta sureste de la península de Nicoya hasta la fosa Mesoamericana, el cual podría asociarse con la falla Barranca o con el levantamiento de Fisher (von Huene et al., 1995). Montero \& Boschini (1991) y Protti et al. (1995b) realizaron algunos mecanismos focales de réplicas de este sismo, que son dominantemente de desplazamiento de rumbo, aunque con planos nodales de direcciones diferentes. Montero (1999) ubicó en el extremo noreste de la falla Barranca, un enjambre de temblores ocurrido en junio de 1978. Asimismo, Güendel et al. (1992) reportan mecanismos focales de diversas geometrías en la entrada del golfo de Nicoya y cerca de Esparza.

Montero (1994a; 1999) mediante argumentos geológicos y sismológicos, asocia el terremoto del 4 de marzo de 1924 (Ms = 7,0), que causó gran destrucción en el sector de Orotina-San Mateo, con 


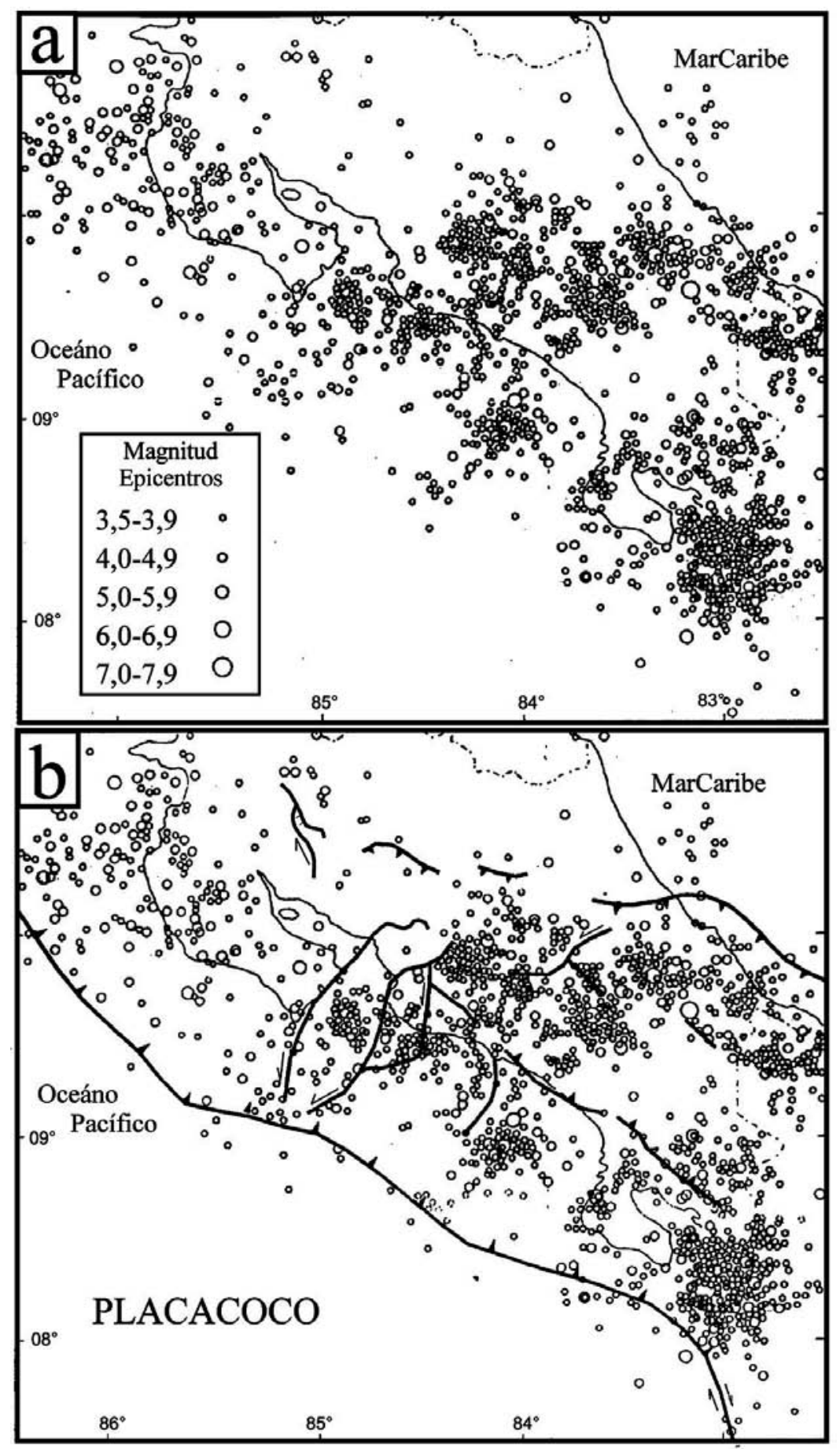

Fig. 5: a) Sismicidad de magnitud $\geq 3,5$, superficial (<20 km) de Costa Rica para abril de 1984-1998. Incluye el ciclo de actividad sísmica ocurrido entre 1990 y 1993 en los cinturones deformados del Centro de Costa Rica y del Norte de Panamá. Se observa claramente una banda ancha de temblores que atraviezan la región central de Costa Rica definiendo el límite oeste de la microplaca de Panamá. b) Fallamiento simplificado del Cinturón Deformado del Centro de Costa Rica y sismicidad cortical. Se muestra la correlación entre ambos. 
la falla Tárcoles. El mecanismo focal realizado por Jacob et al. (1991) es de fallamiento transcurrente con una componente inversa. En la figura 2 se muestra con el número 1 junto con el epicentro propuesto por Montero (1999).

Sismos corticales ocurridos entre 1984 y 1995 pueden asociarse con la falla Tárcoles y con el sistema de falla de Bijagual (Montero, 1999; Fig. 5). Sin embargo, los mecanismos focales realizados muestran gran variedad de geometrías (Montero \& Boschini,1991; Güendel et al.,1992; Güendel et al.,1993; Protti et al., 1995b).

Por lo tanto, los mecanismos focales realizados hasta hoy, muestran diversas geometrías para sismos localizados cerca de las fallas Barranca, Jesús María, Tárcoles y el sistema Bijagual, lo cual no permite concluir acerca del tipo de movimientos sismotectónicos dominantes en esta región.

\section{ARCO INTERNO}

\section{Zona de Arenal-Tilarán}

Se localiza al noroeste del área de estudio e incluye las fallas Cote-Arenal y Chiripa. La falla Cote-Arenal muestra un escarpe prominente de rumbo NW, que en parte limita el sector oriental de la laguna de Arenal. Se asocia con fallamiento normal, donde el bloque occidental desciende. Alvarado (1989a) reporta que tefras eruptadas por el volcán Arenal en los últimos 3000 años, han sido separadas normalmente por la fa1la. En una localidad calcula una velocidad de desplazamiento de $1,8 \mathrm{~mm} /$ año.

Por otro lado, la falla Chiripa tiene un trazo prominente con un rumbo oscilante entre $\mathrm{N} \mathrm{y}$ NW y se ubica del lado oeste y sur de la laguna de Arenal. Localmente presenta escarpes que miran al E y desplaza geoformas recientes. El terremoto del 14 de abril de 1973 (Ms = 6,5) ocurrió en esta falla, tal como lo muestran las réplicas de este sismo localizadas por Matumoto \& Latham (1976). Los mecanismos focales obtenidos para el evento principal y las réplicas (Güendel, 1986; Matumoto \& Latham, 1976), indican que la falla es predominantemente dextral.

\section{Cordillera Volcánica Central}

\section{Sistema de fallas de los volcanes Porvenir-Platanar}

En el sector occidental de los volcanes inactivos Porvenir-Platanar, existen una serie de fallas de rumbo entre $\mathrm{NNW}$ y N-S, las cuales muestran una fuerte componente normal. Las fallas del sistema N-S son las fallas Congo y Porvenir y las NNW son la falla Zarcero y la falla Gata (Alvarado et al., 1988; Montero et al., 1998); las fallas N-S se caracterizan por sus escarpes juveniles con facetamiento rectangular. En la falla Congo, un contraescarpe ha generado la laguna Congo, por represamiento del drenaje (Alvarado et al., 1988). Barquero \& Alvarado (1989) localizaron un enjambre de temblores ocurrido en abril de 1980, cerca de las fallas Gata y Congo. Aunque estos autores relacionan la secuencia de temblores con la falla Gata, es posible también asociarlos con la falla Congo. El mecanismo focal compuesto de estos autores tiene un plano nodal que es similar con el rumbo e inclinación de ambas fallas y sugiere un componente normal y siniestral.

Una falla de importante extensión es la falla Zarcero, de un rumbo oscilante NNW. Cerca de la población de Zarcero, los contraescarpes originaron represamientos de drenaje y paleolagos. En su sector central se divide en dos ramales, ambos con escarpes que miran al este y bastante juveniles. Estos ramales se unen nuevamente al NNW y luego la falla se continua como una sola traza hasta terminar cerca de la unión entre el frente montañoso y la llanura aluvial. Cerca de Zarcero, la falla desplaza normalmente depósitos volcánicos cuaternarios. El 4 de setiembre de 1998 fue localizado un temblor de magnitud 4,0 a $20 \mathrm{~km}$ de profundidad, muy cerca de la traza de la falla Zarcero. El mecanismo focal para este evento es de falla normal y el plano nodal que se inclina al noreste es de rumbo similar a la falla Zarcero, por lo cual se asocia con esta falla (evento 62 en Fig. 3).

En el sector oriental del macizo PorvenirPlatanar se ubica la falla Viejo-Aguas Zarcas de rumbo NNW e importante longitud. Es una falla en tijera (Alvarado et al.,1988), con un valle de 
falla profundo y lineal, que es más escarpado en su sector oriental. Se extiende por unos $25 \mathrm{~km}$ desde el oeste del volcán Poás hasta terminar al norte en la zona de unión entre el frente montañoso y la llanura aluvial.Tres terremotos históricos ocurridos en el límite entre los macizos volcánicos del Platanar-Porvenir y del Poás, el 28 de agosto de 1911 (Ms =6,0), el 6 de junio de 1912 $(\mathrm{Ms}=6,5)$ y el 1 de setiembre de $1955(\mathrm{Ms}=5,8)$ fueron asociados con la falla Viejo-Aguas Zarcas (más probable) o con la falla Carbonera (ver adelante; Alvarado et al., 1988).

Las estribaciones norte a noreste del complejo volcánico Porvenir-Platanar en el límite con la llanura aluvial, muestra un sistema de escarpes ENE a WNW que definen la falla Florencia-La Palmera. Se considera que estos escarpes son la expresión geomorfológica de fallas inversas que se inclinan al sur. Esto debido a su similitud en rumbo y en morfología, con otros escarpes que han sido asociados con este tipo de fallas y que se encuentran en otros sectores de la cordillera volcánica Central (por ejemplo, fallas Alajuela, San Miguel y Guápiles; Borgia et al., 1990) y en el borde norte de la cordillera de Talamanca (fallas de Matina-Siquirres). Muestra dos niveles de escarpes, el superior tiene unos $100 \mathrm{~m}$ de altura y se ubica entre 200 y $400 \mathrm{~m}$ sobre el nivel del mar. El inferior separa la llanura aluvial de las últimas estribaciones de los volcanes Platanar-Porvenir y tiene escarpes de unos 40 a $60 \mathrm{~m}$, que serían los más recientes. La falla Viejo-Aguas Zarcas limita estos escarpes por el lado oriental, mientras que en el lado occidental la falla Zarcero termina en los escarpes de la parte superior.

Barquero \& Alvarado (1989) reportan un enjambre de temblores en setiembre de 1986, con profundidades menores a $5 \mathrm{~km}$, que ocurrió ligeramente al este de la falla Viejo-Aguas Zarcas y al norte de la Florencia-Palmira, el cual relacionan con un fracturamiento de rumbo cercano al norte.

\section{Fallas del sector sumital del volcán Poás}

Se encuentran las fallas Carbonera (zona occidental) y Angel (zona oriental)(Alvarado et $a l .$, 1988). La primera se caracteriza por su rumbo NNW que corresponde con una garganta de falla; tiene una longitud mínima de 6,5 km y muestra prominentes escarpes y divisorias de aguas ligeramente desplazadas en sentido dextral en su sector sur (Alvarado et al., 1988). La falla Ángel tiene rumbo $\mathrm{N} 30^{\circ} \mathrm{W}$ y su extremo sureste parece estar cubierto por cenizas holocénicas (Alvarado et al., 1988).

Un enjambre de temblores ocurrido entre el 5 y 11 de febrero de 1982, con profundidades de alrededor de $5 \mathrm{~km}$, fue localizado cerca de la traza de la falla Angel. El mecanismo focal compuesto de estos eventos es de componente normal en el plano nodal de rumbo $\mathrm{N} 20^{\circ} \mathrm{W}$ y se inclina al NE (Barquero \& Alvarado, 1989).

\section{Falla Alajuela}

Tiene un rumbo oscilante cercano al WNW y se extiende por unos $20 \mathrm{~km}$. Geomorfológicamente, se caracteriza por levantamientos sublineales largos, con escarpes frontales facetados al sur, con uno o dos quiebres de pendiente. La parte trasera presenta contraescarpes de pendiente suave e inclinación al norte. Los levantamientos tienen un relieve entre 50-200 m, un ancho entre 200-400 m, forman un patrón festoneado y su topografía muestra frecuentes saltos en escalera al cruzar los ríos (Borgia et al., 1990). Estos se asocian con un pliegue relacionado con una falla de propagación inversa, que afecta rocas del Cuaternario Tardío y probablemente del Holoceno (Borgia et al., 1990).

Los sismos destructivos del 15 de febrero de 1772 y del 30 de diciembre de 1888, fueron asociados con esta falla (Borgia et al., 1990; Alvarado et al., 1988; Peraldo y Montero, 1994) y enjambres de temblores con magnitudes inferiores a 4,0, han ocurrido al norte del escarpe. Entre estos destaca uno en noviembre de 1989, en el extremo este de esta falla y que fue asociado con una falla de rumbo NE (Barquero \& Alvarado, 1989). Esta última falla probablemente relacionada con la falla Alajuela.

\section{Falla San Miguel}

Es la falla más relevante del sector norte del macizo volcánico del Poás. Tiene un rumbo 
cercano al E-W, una longitud de $15 \mathrm{~km}$ y se caracteriza por su escarpe bastante rectilineo, relativamente poco disectado y con facetamiento rectangular. Aguas arriba del escarpe, los ríos tienen cañones profundos. El escarpe tiene una altura máxima de $160 \mathrm{~m}$ en su parte central, disminuyendo su altura hacia el este y el oeste. Fuentes termales se presentan alineadas con el escarpe (Alvarado et al., 1988). Borgia et al. (1990) han interpretado que este escarpe, representa el flanco delantero de un pliegue anticlinal asociado con una falla de propagación inversa. Esta falla y la de Alajuela se ubicarían a distancias similares del eje del volcán Poás. Borgia et al. (1990) han considerado que ambas fallas son causadas por el deslizamiento gravitacional del edificio volcánico del Poás, ayudado por esfuerzos magmáticos distensivos generados en su eje volcánico. Montero (1994a) estima que los esfuerzos regionales son los que controlan la orientación de estas estructuras. Poca actividad sísmica ha ocurrido en esta región y no se ha asociado directamente con esta falla.

\section{Sistema de fallas del volcán Irazú y del Bajo de la Hondura}

En los terrenos volcánicos cuaternarios del sector occidental y norte del macizo del Irazú, las fallas más importantes son un sistema de fallas de rumbo entre $\mathrm{N}$ y NW, entre las cuales destacan las fallas Lara, Río Sucio y Blanco (Montero \& Alvarado, 1995).

La falla Lara es un lineamiento prominente de rumbo variable entre NW y N. Presenta valles de falla, valles lineales, sillas de falla, trincheras, ríos desplazados y adaptados y escarpes de falla juveniles facetados al oeste (en los tramos N-S de la falla). Las evidencias geomórficas sugieren que tiene componente dextral. Una componente normal es sugerida en los tramos norte donde el bloque este sube.

La falla Río Sucio tiene rumbo NW y se caracteriza por su fuerte prominencia, su valle lineal profundo con un escarpe del lado oriental. Tiene dos relevos distensionales, los cuales sugieren que la falla tiene una componente dextral.
La falla Blanco tiene rumbo NNW y una fuerte prominencia, evidenciada por valles lineales profundos y sillas de falla.

En la zona sumital de volcán Irazú existen varias fallas menores de rumbo $\mathrm{N}$ a $\mathrm{NNE}$, algunas de las cuales pueden considerarse una prolongación de la falla Río Sucio.

Montero \& Alvarado (1995) estudiaron el terremoto de Patillos del 30 de diciembre de 1952 (Ms = 5,9), el cual asocian con la falla Río Sucio, aunque también pudo haberse generado en la falla Lara. También, refieren la ocurrencia de varios enjambres de temblores en esta zona, para los cuales se realizaron mecanismos focales, siendo estos de diversos tipos pero predominando los de desplazamiento de rumbo. Montero \& Dewey (1982) estudiaron una de estas secuencias, obteniendo un mecanismo focal compuesto de desplazamiento de rumbo, con planos nodales de rumbo NW (dextral) y NE (siniestral). Güendel et al. (1992) obtienen un mecanismo focal similar para una secuencia de sismos ocurridos en esta región. Barquero et al. (1995) obtienen mecanismos focales para cuatro eventos con magnitudes entre 3,9 y 4,3 asociados con un enjambre ocurrido en junio de 1991, con soluciones entre normales-transcurrentes e inversas-transcurrentes (Fig. 3). Fernández et al. (1998) estudian la sismicidad de esta zona y reportan la actividad de varias fallas de longitud menor y de rumbo NE ubicadas entre los volcanes Irazú y Turrialba.

\section{Falla Guápiles}

La primera referencia a esta falla aparece en Kesel (1985). Esta falla se ubica sobre el flanco norte del macizo Irazú, la cual se expresa en su parte delantera con un escarpe entre juvenil y disectado de rumbo E-W a WNW. El escarpe mira al norte, tiene fuerte inclinación, facetamiento trapezoidal, una altura entre $150-100 \mathrm{~m}$ en sus sectores oeste y central, que disminuye a unos 40 $\mathrm{m}$ hacia el este donde es muy juvenil y bastante rectilineo. Al sur del escarpe existen lomas limitadas del lado sur por contraescarpes de suave pendiente inclinados en esa misma dirección. Borgia et al. (1990) interpretan que estas geoformas 
se deben a la presencia de un pliegue delantero asociado con una falla de propagación inversa. Boschini (1989) indica que los ríos están encajados aguas arriba del escarpe y tienen difluencias aguas abajo. Asimismo, señala que una terraza aluvial de probable edad Pleistoceno Medio, ubicada entre los ríos Costa Rica y Blanco, tiene una inclinación contrapendiente de entre 7 y 8 grados. Boschini (1989) y Soulas (1989) concuerdan en relacionar este escarpe con fallamiento inverso.

La figura 3 muestra el mecanismo focal 25 para un temblor localizado cerca de la falla Lara, con solución de falla inversa (Fernández, 1995), lo cual concuerda con el tipo de desplazamiento interpretado para la falla Guápiles. También, del lado sur de esta falla, el 30 de setiembre de 1998 se localizó un sismo de magnitud 4,0, con una profundidad de $8 \mathrm{~km}$ y un mecanismo focal inverso, cuyo plano nodal de bajo ángulo se inclina al sur (evento 63 en Fig. 3). Lo anterior concuerda con la interpretación tectónica realizada para esta falla.

\section{Sistema de fallas del sector norte del volcán Turrialba}

Del lado norte del volcán Turrialba, se han detectado varios lineamientos, destacando el sistema de escarpes de Guácimo de rumbo WNW, de prominencia moderada a fuerte, y que limita el flanco norte del volcán (Montero et al., 1995). Los escarpes tienen alturas entre 100 y 200 m sobre el plano aluvial y están poco disectados. Del lado sur de los escarpes se presentan levantamientos alomados y algunos de los ríos que cortan estas geoformas, como el Guácimo, se muestran encajados (Montero et al., 1995). Estos escarpes podrían tener un origen similar a los que se encuentran más al oeste (por ejemplo, los de Guápiles y de San Miguel) o con los escarpes de Matina-Siquirres, ubicados más al este en el borde noreste de la cordillera de Talamanca y que se relacionan con pliegues asociados a fallas de propagación inversa.

La actividad sísmica de esta zona ha sido relativamente baja con algunos temblores aislados y ningún enjambre significativo. No se pueden asociar los temblores con fallas específicas (Montero et al., 1995).

\section{Valle Central y borde norte de la cordillera de Talamanca}

\section{Sistema de fallas de Puriscal y alrededores}

Al oeste y suroeste de Puriscal se ubica la traza de la falla Candelaria, de rumbo noroeste, la cual se ubica en el límite entre el arco interno y el antearco (Fig. 2). No se ha demostrado que este sísmicamente activa, aunque algunos temblores se han ubicado cerca de su traza (Fig. 5). Una secuencia sísmica que ocurrió al este de esta falla, se inició el 26 de febrero de 1989, con un evento principal de magnitud Ms = 4,8 (evento 9 en figura 3). Esta se localizó unos pocos kilómetros al NE de la traza de la falla Candelaria. Güendel (1993) y Dziewonski et al. (1990) obtienen un mecanismo focal de desplazamiento de rumbo similar para el evento principal, con un plano nodal de movimiento dextral NNW y el otro sinistral de rumbo ENE. Güendel (1993) escoge este último como el plano de falla de acuerdo con la dirección dominante de las réplicas que localizó.

En la zona de Puriscal, Montero et al. (1991) reconocieron varias fallas neotectónicas, entre las que destacan la Picagres y la San Antonio, de rumbo $\mathrm{N}$ a NW, con las cuales se asocian estructuras distensivas que sugieren desplazamiento dextral en las fallas (Fig. 3). Montero et al. (1991b) también describen la falla Víbora de rumbo WNW. Algunas de estas fallas también se encuentran en Arias \& Denyer (1991a).

Una serie de temblores de magnitudes $\geq 4,0$, algunos dañinos, ocurrieron entre mayo y julio de 1990, en el sistema de fallas de Picagres y San Antonio. Montero et al. (1991b) obtuvieron mecanismos focales donde predominan los de desplazamiento de rumbo y en los cuales el plano nodal coincidente con el rumbo del anterior sistema de fallas es de tipo dextral (eventos 12 al 24 en Fig. 3). De una forma similar, Fernández (1995) y Güendel et al. (1990) realizan mecanismos focales para los eventos de mayor magnitud de la secuencia, los cuales muestran un plano nodal NW de tipo dextral, concordante con el rumbo de las fallas. El sismo de mayor magnitud de la secuencia fue el del 30 de junio (Ms 5,2). Su mecanismo focal es oblicuo siniestral-inverso (Montero et al., 1991), 
siniestral con pequeña componente normal (informe mensual de junio de 1990 del NEIC; evento 20 en Fig. 3) o normal (Fernández,1995).

Previamente, Montero y Morales (1984) y Güendel et al. (1992) habían localizado varios temblores en la zona de Puriscal, cuyos mecanismos focales compuestos son muy similares a los determinados para la secuencia sísmica de mayo-julio de 1990.

Al suroeste del Valle Central, Montero et al. (1991b) sugieren que la falla Virilla, de rumbo ENE, con expresión geomorfológica débil y con posible movimiento siniestral, fue donde se originó el terremoto del 22 de diciembre de 1990 $(\mathrm{Ms}=5,7)$ (evento 26 en Fig. 3).

\section{Sistema de fallas de los montes del Aguacate y la fa- lla La Garita}

La falla Tárcoles se continua en los montes del Aguacate mediante una serie de fallas secundarias de rumbo cercano al NNE, que son fallas de probable movimiento oblicuo siniestralnormal. Es posible que en esta región también existan fallas inversas de un rumbo cercano al EW, como se observó en la unión de los ríos Grande y Virilla, donde una serie de fallas imbricadas inversas que se inclinan al sur, afectan un lava cuaternaria que sobreyace a un aluvión. Es de esperar que la conexión entre las fallas Tárcoles y La Garita sea mediante un relevo transpresivo.

En el cañón del río Grande, el anterior sistema de fallas se continúa con la falla La Garita, de rumbo NE y que termina al norte en la falla de Alajuela (Montero,1994a). Geomorfológicamente, la falla presenta valles lineales y sillas de fa1la. Esta falla corta los depósitos ignimbríticos cuaternarios. Las estrías observadas en fallas paralelas muestran que es una falla de desplazamiento siniestral. Arias \& Denyer (1991b) sugieren que también tiene componente normal.

\section{Falla Jaris}

Es una falla larga de rumbo NW y caracterizada por valles lineales, sillas de falla, relevos distensivos, ríos desplazados y adaptados y un posible valle aluvial desplazado (el de
Palmichal- Tabarcia). Fue observada en un afloramiento cortando depósitos cuaternarios. Es posible que algunos eventos de la secuencia sísmica de $\mathrm{Pu}$ riscal de mayo a diciembre de 1990, se asocien con esta falla. Montero \& Morales (1984) muestran algunos epicentros localizados cerca de esta falla.

\section{Sistema de fallas Escazú-Belo Horizonte-Aserrí-Jericó}

Sistema de fallas de rumbo NW, que combina movimientos de tipo dextral y de levantamiento especialmente en sus bloques occidentales, el cual se extiende entre el oeste de Escazú y el este de San Gabriel de Acosta. Incluye las fallas Escazú, Belo Horizonte, Aserrí y Jericó.

Al noreste de estas fallas y al sur de la fa1la Alajuela ocurrió una secuencia de sismos en febrero de 1991, destacando el del 16 de febrero, a las 14:20 GMT $(\mathrm{Md}=4,6)$ y el de las 4:30 GMT del 17 de febrero ( $M d=4,2$ ), que causaron daños locales. Sus mecanismos focales son de desplazamiento de rumbo dextral con una componente inversa en el plano nodal de rumbo NW (eventos 27 y 28 en Fig. 3), lo cual corresponde con el rumbo de las fallas Escazú, Belo Horizonte-Jericó y Aserrí. Por otro lado, en el plano nodal NE el movimiento es sinistral y tendría un rumbo similar a la falla Virilla, la cual se encuentra hacia el oeste, por lo cual esta sismicidad también se podría relacionar con una extensión de esta falla hacia el noreste. El 13 de febrero de $1993(\mathrm{Md}=4,1)$ ocurrió otro temblor en esta zona, con un mecanismo focal normal en planos nodales de rumbo NW (evento 46 en Fig. 3; Fernández, 1995).

Sismos superficiales se han ubicado cerca de las fallas Belo Horizonte-Escazú-Aserrí. Un mecanismo focal realizado por Fernández (1996) es de tipo inverso y tiene planos nodales de rumbo E-W. Fernández (1995) realizó varios mecanismos focales con fallamiento predominantemente normal, aunque los rumbos de los planos nodales no concuerdan con los de las anteriores fallas (Fig. 3). Por lo tanto, la sismotectónica muestra varios tipos de soluciones focales, lo cual no permite aclarar cual es el tipo de fallamiento dominante de esta zona. 


\section{Falla Frailes}

Es una falla de rumbo NW a E-W. Su trazo noreste tiene expresión moderada a fuerte, con valles lineales alineados y sillas de falla. Este tramo de la falla Frailes se continúa al noroeste con la falla Jericó. El sector E-W muestra escarpes del lado norte de la falla, que al oeste parecen unirse con la falla Jaris (Montero, 1994b). De acuerdo con Arias y Denyer (1991b), en este sector la falla es inversa, inclinándose al norte.

El temblor del 9 de agosto de 1991 (Ms = 4,8), que causó daños menores, se asoció con la falla Frailes (Montero,1994b). Esta conclusión se basó en que su epicentro, así como las de las réplicas se localizaron muy cerca de la traza de esta falla. Además, este autor reportó una serie de pequeños deslizamientos alineados con la falla y el área de daños está elongada en la dirección de la falla (Barquero et al., 1991). Además, el plano nodal NW del mecanismo focal de este temblor coincide con el rumbo de la falla, indicando que la misma es de desplazamiento de rumbo dextral con una leve componente normal (evento 42 en Fig. 3).

\section{Sistema de fallas Agua Caliente-Río Azul-Cipreses}

Es un sistema de fallas con rumbos variables entre ENE y WNW que incluye las fallas Agua Caliente, Río Azul y Cipreses. Esta última además se caracteriza por terminar en una serie de pliegues de rumbo NW.

Montero \& Miyamura (1981) sugirieron que la falla Agua Caliente originó el terremoto de Cartago del 4 de mayo $(\mathrm{Ms}=6,4)$. Otro temblor que se puede asociar con estas fallas fue el del 21 de febrero de 1912, que causó muchos daños en Tres Ríos y alrededores. Dos enjambres de temblores ocurridos entre el 5 y el de 10 de junio de 1994 y entre el 25 de octubre y el 2 de noviembre de 1994, fueron localizados sobre la traza de la falla Agua Caliente, al sur de San José. El sismo de mayor magnitud de estas secuencias sísmicas ocurrió el 28 de octubre de 1994 (Md = 4,2). Su mecanismo focal es de fallamiento de desplazamiento de rumbo siniestral en el plano nodal de rumbo ENE, lo cual coincide con el rumbo de la traza de la falla Agua Caliente (evento 52 en Fig. 3).

\section{Falla Navarro}

La falla Navarro con un rumbo ENE a NE, es una falla de desplazamiento siniestral que en su extremo oeste sigue el borde norte del valle del río Navarro. Al salir de este valle al este, modifica su rumbo al NE y en esta zona debe de tener además una componente normal, donde el bloque este baja. Sobre la falda sur del volcán Turrialba, la falla retoma un rumbo ENE. Al norte de Turrialba se pierde su traza.

La falla Navarro presenta un valle de falla profundo con paleodepósitos de fuentes termales (valle del río Navarro), sillas de falla, trincheras de falla, quiebres de ladera y escarpes locales. Una trinchera realizada al sur de Paraíso mostró que es una falla activa con una zona de falla de al menos unos $50 \mathrm{~m}$ de ancho (GEOMATRIX CONSULTANTS, 1994). Al este de Paraíso parece cortar la colada de Cervantes, cuya edad se ha calculado entre 13500 y 23000 años (ver Alvarado, 1989b).

Un enjambre de temblores ocurrido en setiembre de 1980, se ubicó en el extremo oeste de esta falla (Aguilar, 1984). Sin embargo, en esta zona se localiza el extremo sur de la falla Cangreja, que tiene rumbo NW : Los mecanismos focales compuestos de Aguilar (1984) tienen soluciones de fallamiento inverso, con planos nodales de rumbos predominantes NW, que parecen concordar con el rumbo de la falla Cangreja. La distribución de los daños del terremoto de Paraíso-Orosi del 9 de agosto de 1951 (M 5,0), sugiere que este evento se generó en la falla Navarro.

\section{Falla Atirro}

La falla Atirro tiene rumbo NW y es bastante larga. Al sureste del relevo transpresivo del cerro Mirador tiene una traza simple y se caracteriza por sus valles lineales prominentes, a lo largo de los cuales se encuentran claras evidencias de su movimiento dextral (Montero et al., 1993; Montero, 1994a). Al noroeste del anterior 
cerro se divide en dos trazas, siendo la oeste la falla Tucurrique y la este la falla Turrialba. La falla Turrialba pasa ligeramente al oeste de la población de Turrialba. Al cruzar el río Reventazón origina un desvío dextral del mismo y luego sigue del lado oeste del cerro Atirro y se continua cerca del borde oeste del cauce del río Atirro, hasta alcanzar la falla Atirro.

La falla Tucurrique de rumbo NW, muestra varias evidencias neotectónicas, que indican que es una falla dextral, aunque localmente también tiene componente de levantamiento en el lado este. Geomorfológicamente se caracteriza por tener una expresión moderada a fuerte, muestra valles alineados, rios adaptados o desplazados dextralmente, sillas de falla, aluviones levantados (por ejemplo, donde corta el río Pejibaye), escarpes que miran tanto al noreste como al suroeste y trincheras de falla.

La figura 3 muestra el evento 7 cuyo epicentro se ubica en el lomo de presión del cerro Mirador. El mecanismo focal de este sismo muestra una fuerte componente inversa, en concordancia con el origen del mismo. No se ha determinado actividad sísmica asociada con los ramales Turrialba y Tucurrique, aunque una serie de evidencias geomórficas sugieren su actividad cuaternaria y posiblemente holocénica.

\section{Sistema de fallas transtensionales de Simari}

Al oeste de la falla Atirro, existe un sistema de fallas posiblemente siniestrales de rumbo ENE, con estructuras transtensionales incipientes. Tiene rumbo oscilante, aunque en términos generales es de tendencia ENE con tramos más cortos de rumbo WNW. Geomorfológicamente se caracteriza por una prominencia moderada a débil, valles lineales, sillas de falla y escarpes facetados mirando al sur. En el extremo este, los escarpes parecen muy juveniles y con facetamiento rectangular. Parece originar desviaciones izquierdas en algunos ríos.

La secuencia sísmica de Pejibaye de junio de 1993, que incluye dos terremotos de magnitud intermedia, el 10 de junio $(\mathrm{Ms}=5,6)$ y el 13 de junio $(\mathrm{Ms}=5,2)$, se pueden asociar con este sistema de fallas. La figura 3 muestra la cercanía espacial de los temblores 47 a 50, que son los de mayor magnitud de esta secuencia, con el sistema de fallas de Simari. Sus mecanismos focales confirman que son fallas siniestrales con una componente normal. El rumbo de los planos nodales concuerda con el de las fallas Simari.

\section{Falla Buenavista}

Al sur del sistema de falla de Simari se ubica la falla Buenavista, originalmente reconocida por Boschini et al. (1988). Tiene rumbo aproximado N-S y sigue un valle de falla escarpado. Los anteriores autores consideran que esta falla originó el terremoto de Buenavista del 3 de julio de 1983 (Ms = 6,5), cuyo mecanismo focal tiene un plano nodal de rumbo cercano al norte que indicaría una falla de desplazamiento dextral (evento 6 en Fig. 3).

\section{TRASARCO}

\section{Borde noreste de la cordillera de Talamanca}

El terremoto de Limón del 22 de abril de $1991(\mathrm{Mw}=7,7)$ puso en evidencia la importante actividad neotectónica que presenta el sector noreste de la cordillera de Talamanca.

\section{Falla Kabébeta}

La falla Kabébeta tiene rumbo NW a WNW y prominencia moderada a fuerte. La falla muestra escarpes mirando al oeste, valles lineales, ríos desplazados y sillas de falla. Las evidencias geomorfológicas y el contexto tectónico sugieren que es una falla de alto ángulo que combina desplazamiento dextral e inverso, con el bloque este levantándose. Esto último sugiere que es una falla inversa trasera (backthrust) con respecto a la falla de Limón, fuente del terremoto del 22 de abril de 1991 (Mw = 7,7). En el extremo noroeste, la falla se divide en dos ramales. El ramal del oeste muestra sillas de falla, contraescarpes que miran al sur y valles lineales transversales al rumbo dominante del drenaje. Estas características geomórficas sugieren que su lado este se levanta, provocando la formación de nuevas divisorias 
de dirección NE en el lado oriental de la falla. Este ramal sugiere tener un desplazamiento dominantemente inverso. El ramal oriental es más rectilineo y se caracteriza por sus valles lineales y sillas de falla.

Una réplica del terremoto de Limón de 1991 de magnitud Ms 6,1, se localizó muy cerca de esta falla. Su mecanismo focal es de desplazamiento de rumbo bastante puro, donde el rumbo del plano nodal que coincide con el rumbo de la falla es dextral (evento 31 en Fig. 2); esto corresponde parcialmente con las evidencias de desplazamiento morfológicas de la falla.

\section{Falla Ayil}

Es un lineamiento prominente de rumbo NW, de alto ángulo y se identifica por sus valles prominentes alineados y sillas de falla igualmente alineadas. Un gran deslizamiento originado a lo largo de su traza ha originado la laguna de Ayil.

Una réplica del terremoto de Limón de 1991 ocurrió al oeste de esta falla, con mecanismo focal de tipo inverso en planos nodales de rumbo cercano al E-W (evento 36 en Fig. 2).

\section{Falla Pacuare}

Esta falla tiene rumbo NS en su sector norte y NW en su sector sur. Tiene prominencia moderada a fuerte y muestra valles lineales y sillas de falla. Sigue parcialmente el valle del río Peje hasta su confluencia con el río Pacuare y luego se ubica cerca del valle de este último río en diversos sectores de su trazo.

Una réplica del terremoto de Limón de 1991de magnitud $\geq 4,0$, que ocurrió al oeste de esta falla, tuvo un mecanismo de desplazamiento de rumbo, donde el plano de rumbo cercano al N-S es de desplazamiento dextral (evento 35 en Fig. 3).

\section{Fallas de Matina-Siquirres}

El límite entre el sector noreste de la cordillera de Talamanca y la llanura aluvial, entre las poblaciones de Siquirres y puerto Limón, muestra una serie de escarpes de rumbo E-W. Estas geoformas, bastante juveniles, aparecen descritas en Boschini (1989), quién se basó en Soulas (1989). Los escarpes tienen alturas máximas entre 200 y $300 \mathrm{~m}$, aunque los más recientes tienen escarpes de menos de $100 \mathrm{~m}$ de altura. En algunos sectores presentan un único escarpe, pero en otros sectores existen varias lineas de escarpes a diferentes alturas, como es el caso del sector comprendido entre el río Cimarrones y el río Barbilla (Boschini, 1989). En algunos sectores se presentan terrazas aluviales levantadas. Es frecuente observar que los ríos aguas arriba de los escarpes están encajados y tienen difluencias aguas abajo. Soulas (1989) considera que estos escarpes son originados por fallamiento inverso, que se puede dividir en varias escamas, cuando existen escarpes múltiples.

Boschini (1989) reporta la ocurrencia de temblores someros al sur y norte de los escarpes, basándose en datos obtenidos de una red sismológica local. Asimismo, realizó mecanismos focales compuestos de desplazamiento de rumbo, los que pueden estar relacionados con el sistema de fallamiento inverso, indicando además que los temblores que se ubican al norte de los escarpes bajo la llanura aluvial, podrían señalar la presencia de fallas ciegas. Considera que el terremoto de Limón del 7 de enero de 1953 (M 5,3-5,8) se puede asociar con este sistema de fallas. Esto último explicaría los levantamientos geodésicos ocurridos entre 1949 y1953, reportados por Miyamura (1975). Una réplica del terremoto de Limón de 1991 (Ms = 4,8), que ocurrió ligeramente al sur de este sistema de escarpes, tuvo un mecanismo focal de falla inversa, de rumbo similar a los escarpes (evento 43 en Fig. 2). Las anteriores evidencias muestran que este fallamiento está activo.

\section{Falla Río Blanco}

Se ubica ligeramente al oeste de puerto Limón y es de desplazamiento de rumbo siniestral con componente normal. Tuvo desplazamiento cosísmico durante el terremoto de Limón del 22 de abril de $1991(\mathrm{Mw}=7,7)$ (Denyer et al., 1994). En la figura 2 se muestra la interpretación de la relación de esta falla con el sistema de fallamiento inverso. 
Esta falla es una rampa lateral entre el sistema de fallas inversas de Matina-Siquirres y el sistema de fallamiento inverso del Cinturón Deformado del Norte de Panamá, al cual pertenece la falla de Limón.

\section{Falla de Limón}

La falla de Limón es el segmento de falla del sistema de fallamiento inverso del Cinturón Deformado del Norte de Panamá, que se localiza bajo la Baja Talamanca y el litoral caribe, la cual se deslizó durante el terremoto de Limón del 22 de abril de 1991 (Mw = 7,7; evento 29 en Fig. 2). Asociado con este terremoto ocurrió un levantamiento cosísmico que fue entre 0,5-1,5 m, desde Puerto Limón hasta cerca de la frontera con $\mathrm{Pa}$ namá, a lo largo del litoral caribe de Costa Rica. Existe evidencia de varios levantamientos paleosísmicos en esta falla, indicados por paleoarrecifes levantados hasta $60 \mathrm{~m}$ arriba del nivel del mar, que muestran muescas en forma de $\mathrm{V}$ horizontales y con paleoplataformas de abrasión que se extienden por varias decenas de metros (Denyer et al., 1994). Denyer (1998) estima una velocidad de levantamiento de $1,8 \mathrm{~mm} / a n ̃ o$ durante los últimos 30000 años. De acuerdo con los datos de la sísmica, el sistema de fallamiento inverso de bajo ángulo termina en la zona comprendida entre el talud y la plataforma continental, en una serie de fallas lístricas y pliegues delanteros asociados (Sheehan et al., 1990; Fernández et al., 1994; Silver et al., 1995). Las réplicas del terremoto de Limón de 1991 indican la existencia de una falla basal que alcanza profundidades cercanas a los $20 \mathrm{~km}$ (Ponce et al., 1994).

\section{Falla Sukut}

Falla de rumbo NW que se inicia al noroeste en una zona transpresiva incipiente. Tiene dos ramales, siendo la falla oriental prominente y continua y la falla occidental discontinua y poco desarrollada. La geometría de esta estructura sugiere que la falla tiene componente dextral. La falla se caracteriza por valles lineales, sillas de falla y escarpes facetados que miran al sur. Esto último sugiere que la falla también tiene una componente inversa a lo largo de una falla de alto ángulo. Esta componente inversa implicaría que es una falla trasera que compensa los movimientos de levantamiento que se originan en la falla de Limón.

En el mapa geológico de Costa Rica de Sandoval et al. (1982), se muestra esta falla con un trazo similar al que proponemos con base en el análisis fotogeológico. La geología del Terciario concuerda con la interpretación de que el bloque oriental se levanta.

Dos réplicas del terremoto de Limón de 1991 (eventos 33 y 37 en Fig. 2), de magnitud $\geq 4,0$, se localizaron en la posible continuación de esta falla en territorio panameño, donde aflora un sistema de pliegues cuaternarios (Cowan et al., 1998). Los mecanismos focales de estos temblores son de fallamiento inverso bastante puro con planos nodales de rumbos coincidentes con el rumbo de la falla Sukut.

\section{EL CINTURÓN DEFORMADO DEL CENTRO DE COSTA RICA: CARACTERÍSTICAS ESTRUCTURALES}

Definimos el Cinturón Deformado del Centro de Costa Rica (CDCCR) como el sistema de fallas corticales que actúa como el límite oeste de la microplaca de Panamá con la placa Caribe.y que atravieza la región central del país. Incluye las fallas ubicadas entre el borde pacífico al este de la fosa Mesoamericana y las de la parte central del arco interno hasta que el sistema de fallas se une en el caribe con el Cinturón Deformado del Norte de Panamá (CDNP). Incorpora fallas de diversos desplazamientos, pero en general son dominantemente de desplazamiento normal en el antearco (sector pacífico), mientras que en el arco interno son inversas de rumbo WNW en el sector norte y en la parte interna del cinturón son de desplazamiento de rumbo dextrales (NW) y siniestrales (ENE a NE), estas últimas de mayor longitud. Al este, el CDCCR se une con un sistema de fallas donde dominan las inversas y los pliegues, ambos de rumbo NW, que forman parte del CDNP. A continuación sintetizamos las características estructurales de los diversos sectores del CDCCR. 
La interpretación sísmica de la zona marina de la entrada del Golfo de Nicoya, frente a Herradura y Quepos, indica la existencia de un sistema de fallas normales con componente de desplazamiento de rumbo, las cuales desplazan secuencias sedimentarias del Plioceno y posiblemente hasta del Cuaternario (Barboza et al., 1995; Fig. 4). Entre las anteriores fallas destacan dos con componente siniestral que limitan la cuenca de tracción de Nicoya (Barboza et al., 1995; Fernández et al., 1997), las cuales en tierra firme se denominan las fallas Barranca y Tárcoles. También destaca en la zona continental el sistema de fallas N-S de Bijagual, con movimiento combinado siniestral-normal, que parece continuarse en el área marina (Fernández et al., 1997; Fig. 4). El anterior fallamiento que combina movimiento normal y siniestral se asocia con la tensión y con el movimiento horizontal debido al desplazamiento hacia el este-noreste de la microplaca de Panamá con respecto a la placa Caribe.

En el arco interno, tenemos que al noroeste de Costa Rica, la falla más relevante es el sistema de fallas dextral de Chiripa y la normal de Cote-Arenal, que han originado la cuenca de tracción de Arenal, donde se ubica la laguna del mismo nombre. Estas fallas se pueden asociar con el escape tectónico del bloque occidental, donde se ubica la península de Nicoya, debido al efecto de la colisión del levantamiento del Coco y los montes submarinos ubicados al este de la frontera suace-rugosa.

En el centro de Costa Rica existen varios sistemas de fallas. En el sector norte del arco interno domina el fallamiento inverso. Al oeste se inicia con las fallas de La Palmera y de Aguas Zarcas, ubicadas en el borde norte de los edificios volcánicos de Platanar-Porvenir. En el extremo oeste estas fallas tienen rumbo WSW. El sistema de fallamiento inverso se continúa con las fallas de Alajuela y de San Miguel, que limitan respectivamente los bordes norte y sur del volcán Poás; el escarpe de Guápiles que limita el borde norte del volcán Irazú; la falla de Guácimo que limita el borde norte del volcán Turrialba; y las fallas Siquirres-Matina, que limitan el borde nornoreste de la cordillera de Talamanca. Las anteriores fallas originan un cinturón continuo de fallamiento inverso de rumbo variable pero cercano al WNW. Algunas de las anteriores fallas son de propagación inversa que terminan en pliegues delanteros, como son las fallas de Alajuela, San Miguel y Guápiles (Borgia et al., 1990). Se sugiere que este modelo de deformación puede ser aún más extenso y presentarse también en asociación con otros escarpes, cuyas morfologías muestran características similares al de la falla de Alajuela. En concordancia con Soulas (1989), en otros casos se infiere la existencia de varias escamas de fallamiento inverso, como lo reflejan la presencia de escarpes de diferentes alturas y morfologías.

El sistema de fallas WNW de Siquires-Matina se une con la falla de Limón mediante la falla de transferencia de Río Blanco. Al este-sureste de esta falla ocurre un cambio de rumbo en el sistema de fallamiento inverso, dado que el primero es WNW mientras que el segundo es NW. La falla de Limón forma parte del CDNP, un sistema de fallas inversas y pliegues que alcanza el piso marino en la zona comprendida entre el talud y la plataforma continental. Este último, además de bordear el litoral caribe de Costa Rica al sureste de puerto Limón, se continúa en el sector marino norte de Panamá, definiendo el límite norte de la microplaca de Panamá. Las características estructurales y tectónicas del CDNP se detallan en Case \& Holcombe (1980), Silver et al. (1990) y Silver et al. (1995).

Aunque el CDNP tiene continuidad estructural con el cinturón de fallas inversas de la región continental norte de Costa Rica, comprendido entre Siquirres-Matina y Florencia-La Palmera, se considera que este último tiene características estructurales y tectónicas particulares, como son su diferente rumbo, su ubicación en el sector norte del arco interno y dentro de una corteza continentalizada, por lo cual se prefiere incluírla dentro del CDCCR. Además, en esta última zona existe una orientación diferente del esfuerzo principal máximo el cual es cercano al N$\mathrm{S}$, mientras que en el CDNP es NE.

La parte interna de la zona de deformación del CDCCR es dominada por fallas de desplazamiento de rumbo, distinguiéndose dos sistemas: el de rumbo entre ENE y NE que es 
predominantemente siniestral y el de rumbo entre NNW y NW que es característicamente dextral.

El sistema de fallas dextral incluye en la cordillera volcánica Central posiblemente las fallas Lara y Río Sucio. En el sector norte de la cordillera de Talamanca a las fallas Candelaria, Picagres, San Antonio, Jaris, Escazú-Belo Horizonte-AserríJericó, Frailes y Atirro con sus ramales Turrialba y Tucurrique. Algunas de estas fallas presentan también componentes normales o inversas. Además, se encuentran relevos distensivos y compresivos asociados con estas fallas transcurrentes.

El sistema de falla siniestral de rumbo entre NE y ENE incluye las fallas La Garita, Viri1la, Agua Caliente, Tulín, Navarro y Simarí. La falla La Garita parece formar parte del sistema Barranca, Jesús María, Tárcoles, Bijagual, con el cual se asociaría mediante un sistema de fallas en los montes del Aguacate.

Las diversas evidencias indican que tanto el sistema de fallas de desplazamiento de rumbo dextral como el siniestral están activos, porque la actividad sísmica reciente ha ocurrido tanto en fallas de desplazamiento de rumbo siniestral como en el dextral. Así, la actividad sísmica de $\mathrm{Pu}-$ riscal de mayo-julio de 1990 ocurrió en el sistema de fallas de Picagres-San Antonio que es dextral con componente normal. El temblor del 19 de agosto de 1991 ocurrió en la falla Frailes, que es dextral. Por otro lado, la secuencia de Pejibaye, que tuvo su actividad máxima entre el 10 al 13 de julio de 1993, ocurrió en el sistema de falla Simarí que es siniestral-normal y el terremoto de Piedras Negras del 22 de diciembre de 1990 (Ms 5,7), se infiere ocurrió en la falla siniestral de Virilla.

Por otro lado, estructuralmente se observa que en unos casos las fallas siniestrales parecen cortar e interrumpir la continuidad de las fallas dextrales y en otros casos parece ocurrir lo contrario. Así, las fallas dextrales de Tucurrique y Turrialba, se continúan al noroeste hasta la falla Navarro. Por otro lado, la falla Navarro termina ligeramente al este de la falla Frailes. Se pueden mencionar otros casos similares. Lo anterior indica que la deformación en la región central de Costa Rica ocurre tanto en fallas dextrales como siniestrales.
Se observa que entre más cercano al N-S sea el rumbo de las fallas de desplazamiento horizontal, mayor es su componente normal. Las N$\mathrm{S}$ llegan a ser normales puras, aunque hay excepciones. Ejemplos de este tipo de relaciones estructurales se observa en las diferentes regiones morfotectónicas, sin embargo, el mayor número de fallas con componente normal se encuentra en la cordillera volcánica Central. En esta región tenemos como excelentes ejemplos las fallas Zarcero, Congo, Porvenir y algunos sectores de la Lara. Esto evidencia una extensión en sentido EW, lo cual está de acuerdo con el campo de esfuerzos regional deducido por Montero \& Morales (1990), Montero (1994a), Kolarsky et al. (1995) y López (1999) en la región central de Costa Rica, donde el esfuerzo compresivo horizontal máximo es cercano al N-S y el esfuerzo principal mínimo horizontal es E-W.

\section{MODELO DE DEFORMACIÓN Y EL BORDE OESTE DE LA MICROPLACA DE PANAMÁ}

La deformación neotectónica que ocurre en el Cinturón Deformado del Centro de Costa Rica, se debe a la colisión del levantamiento del Coco con el sureste de Costa Rica, el cual genera un patrón de esfuerzos principales máximos que tiene forma de abanico y cuya orientación varía entre $\mathrm{N}-\mathrm{S}$ en el centro de Costa Rica a NE en la Baja Talamanca (Montero \& Morales, 1990; Montero, 1994a; Kolarsky et al.,1995; López, 1999; ver Fig. 1). Estos esfuerzos se propagan desde la zona de colisión enfrente de Osa y Burica, en el Pacífico sur de Costa Rica, hasta el borde caribe al sureste de puerto Limón y hacia el límite externo de la cordillera volcánica Central. La zona de deformación que ha generado este evento de colisión tiene un ancho de más de cien kilómetros en la región central de Costa Rica y que alcanzar a afectar también la Baja Talamanca. Los efectos neotectónicos provocados por esta indentación han sido documentados por diversos autores, tanto en el lado pacífico (Wells et al., 1988; Gardner et al., 1992; Kolarsky et al., 1995) como en el caribe (Collins et al., 1995; 
Kolarsky et al., 1995). Este evento de colisión viene ocurriendo desde hace aproximadamente 3,6 millones de años (Collins et al., 1995). Considerando a su vez que el istmo de Panamá colisionó con Colombia durante el Plioceno (Mann \& Kolarsky, 1995) y que este proceso generó los cinturones Deformados del Este y Norte de Panamá, tenemos que junto con el Cinturón Deformado del Centro de Costa Rica, se definen claramente los diferentes límites de la microplaca de Panamá con respecto a la placas circundantes (Caribe, Coco y Nazca).

Veamos los detalles de la deformación que ocurre en los diferentes sectores del Cinturón Deformado del Centro de Costa Rica. En el antearco, la evidencia de la neotectónica, de la sismicidad y de la sismotectónica, incluyendo la fuerte sugerencia de que el terremoto de 1924 se originó en la falla Tárcoles, señalan que en esta zona ocurre un intenso fallamiento cortical, que se localiza encima de la zona de convergencia de placas y que es parte del extremo oeste del límite difuso que existe entre la placa del Caribe y la microplaca de Panamá. En esta región el fallamiento es predominantemente normal con una componente siniestral. La tracción existente en esta región con componente siniestral se explica por el movimiento relativo al noreste de la microplaca de Panamá con respecto a la placa Caribe, inducido por la colisión del levantamiento del Coco.

Como se mencionó anteriormente, existe un sistema externo de fallamiento inverso en la región central de Costa Rica, que bordea el sector norte de la cordillera volcánica Central y que se continúa entre Siquirres y Puerto Limón. En este último lugar, el sistema de fallas inversas cambia su rumbo del WNW al NW y sigue hacia el sureste por el caribe de Costa Rica y el norte de Panamá. Este sistema de fallas inversas correspondería con el límite externo existente entre la microplaca de Panamá y la placa Caribe entre el centro y el caribe de Costa Rica y el norte de Panamá.

En el sector caribe de Costa Rica y Panamá esta deformación se origina por el sobrecorrimiento continental con respecto al basamento oceánico de la cuenca de Colombia. La frontera entre ambas provincias tectónicas es el sistema de falla inverso de Limón, cuya falla basal se inclina hacia el SW y alcanza profundidades de hasta 20-25 km bajo la Baja Talamanca (Ponce et al., 1994; Montero et al., 1994). Es posible que este sistema de fallas inversas sea más somero y alcance profundidades máximas de 10 a $15 \mathrm{~km}$ entre puerto Limón y Siquirres y bajo la cordillera volcánica Central.

Detrás del sistema externo de fallas inversas del CDCCR, existen tanto fallas normales como de desplazamiento de rumbo dextrales y siniestrales con componentes normales e inversas, que tienen diferentes distribuciones espaciales dentro de las zonas de deformación. En el sector oeste de la cordillera volcánica Central, al sur del sistema externo de fallas inversas, parecen predominar las fallas normales, de rumbo cercano al N. Estas fallas demuestran la extensión en sentido cercano al E-W existente en esta región. Al centro y este de la cordillera volcánica Central, hay fallas transcurrentes y normales.

Dentro del Valle Central y el borde norte de la cordillera de Talamanca dominan fallas siniestrales con rumbos entre NE a ENE, las cuales muestran un patrón de fallas en échelon, que está constituído por las fallas Tárcoles, La Garita, Virilla, Agua Caliente, Navarro y Simarí. Estas fallas se asocian con fallas inversas como son las fallas de Alajuela y Cipreses o elementos transpresivos como el de Aguacate. Estas fallas permiten la traslación horizontal de la microplaca de Panamá con respecto a la placa Caribe hacia el noreste y su patrón geométrico está controlado por los esfuerzos generados por la colisión del levantamiento del Coco (Montero, 1994a).

El fallamiento dextral se localiza principalmente dentro de la cordillera de Talamanca y normalmente se localiza al sur del fallamiento siniestral. Este permite el desplazamiento o la rotación entre los bloques que se localizan dentro de la zona de deformación y favorecen movimientos hacia los bordes compresivos, los cuales marcan el límite externo de la microplaca Panamá. Igualmente, su patrón geométrico es bien explicado por los esfuerzos máximos en abanico generados desde la zona de colisión en el sur de Costa Rica (Montero, 1994a). 
En la Baja Talamanca, en el sector noroeste del Cinturón Deformado del Norte de Panamá, en la parte trasera del sistema de fallamiento inverso, predominan fallas de desplazamiento dextral-inverso como parece ser las fallas Atirro, $\mathrm{Pa}-$ cuare y Sukut. Esto nuevamente lo explica el patrón de esfuerzos generados desde el sur de Costa Rica por el proceso de indentación tectónica (Montero, 1994a; Kolarsky et al., 1995).

Con respecto al movimiento relativo $\mathrm{Ca}$ ribe-microplaca de Panamá, este parece ser dominantemente hacia el ENE al sureste de puerto Limón $\left(74^{\circ}\right.$ considerando el rumbo del vector deslizamiento de la falla asociada al terremoto de Limón del 22 de abril de 1991, Mw 7,7; Goes et al., 1993). Sin embargo, a través del centro de Costa Rica este parece ser más hacia el norte, debido a la dirección de los esfuerzos máximos propagados desde la zona de colisión en este sector (Fig. 1).

La actividad sísmica cortical recopilada para el período 1990-1995 ( $\mathrm{M} \geq 3,5)$, indica que esta se concentra en el margen pacífico, a lo largo de la región central y en la Baja Talamanca confirmando la existencia del Cinturón Deformado del Centro de Costa Rica (Fig. 5). Esta sismicidad define claramente el límite oeste de la microplaca de Panamá con respecto a la placa Caribe y corresponde con la región donde han sido identificadas las principales fallas corticales del país.

Los anteriores conceptos son entonces compatibles con el modelo sugerido por autores anteriores que consideran que a través de Costa Rica existe un límite entre la microplaca de Panamá y la placa Caribe (Fan et al., 1993; Fisher et al., 1994; Montero, 1994a). Sin embargo, en este trabajo se ha definido claramente el fallamiento neotectónico existente dentro de esta región y su relación con la sismicidad y la sismotectónica; el mismo se ha denominado el Cinturón Deformado del Centro de Costa Rica. Por tanto, las diferentes evidencias apoyan el modelo de un límite oeste de la microplaca de Panamá con relación a la placa Caribe a través de la región central de Costa Rica. Esta deformación neotectónica es controlada por la colisión del levantamiento del Coco con el sur de
Costa Rica. Como describió Montero (1994a), este proceso tectónico origina una indentación del margen continental sur del país, el cual provoca un campo de esfuerzos máximos en forma de abanico que controla los desplazamientos de las diversas fallas neotectónicas que hemos descrito (Fig. 1). Las fuerzas asociadas a la colisión provocan el desplazamiento tectónico de la microplaca de Panamá con respecto a la placa Caribe, generando una fuerte compresión sobre el sector noreste del caribe costarricense y hacia el nornoreste en la cordillera volcánica Central. La distensión combinada con desplazamiento siniestral en el sector trasero oeste de la microplaca de Panamá confirma su movimiento al este-noreste.

\section{DISCUSIÓN Y CONCLUSIONES}

La existencia de una zona de fallamiento transcurrente siniestral a través de la región central de Costa Rica fue originalmente sugerida por Montero \& Dewey (1982). Luego, Astorga et al. (1991) propusieron la existencia de la zona de falla transcurrente de Costa Rica, que ubicaron en el centro del país y que consideraron dividía a Costa Rica en dos bloques. Estos autores sugerieron que este fallamiento había estado activo durante el Terciario. Posteriormente, a raiz de la actividad sísmica ocurrida en Costa Rica entre 1990 y 1993, varios autores propusieron la existencia de un límite incipiente entre la microplaca Panamá y la placa Caribe a través de la región central de Costa Rica, la cual estaba dominada por fallamiento de tipo siniestral (Montero, 1990; Goes et al., 1993; Fan et al., 1993; Güendel \& Pacheco, 1992; Fisher et al., 1994; Montero, 1994a). Montero (1994a) sugirió que esta zona de fallamiento es bastante más compleja que una simple frontera de fallamiento siniestral, como lo propusieron originalmente Astorga et al. (1991) y Fan et al. (1993), entre otros. Esto se demuestra claramente en este trabajo, donde se observa que efectivamente es válido el modelo de un límite incipiente entre la microplaca Panamá y la placa Caribe, pero que a diferencia de autores anteriores, es más conveniente vizualizar esta zona 
de deformación como una zona ancha constituída por varios sistemas de fallas con diferentes tipos de deslizamientos. Las características geométricas y de desplazamiento de estas fallas están determinadas por el patrón de esfuerzos máximos en forma de abanico que resultan de la colisión del levantamiento del Coco con el sureste de Costa Rica (Fig. 1). Este último proceso es el motor que determina las características estructurales y tectónicas de la zona que se denomina en este trabajo como el Cinturón Deformado del Centro de Costa Rica.

Recientemente, Fernández (1996) y Fernández \& Pacheco (1998), consideraron que no existen evidencias geológicas, sismológicas ni sismotectónicas suficientes que apoyen la existencia de un límite transcurrente siniestral en la parte central del país, observando que los dos sistemas dominantes de fallamiento son noreste y noroeste donde este último es el más importante. Sin embargo, estos autores solo estudiaron una región limitada del centro de Costa Rica y consideraron, al igual que otros autores, un modelo simple de falla siniestral, no observando que este es en realidad una amplia zona de deformación, integrada por diversas zonas de fallamiento, las que en conjunto constituyen un límite incipiente de placas.

En conclusión, en este trabajo se muestra claramente que el Cinturón Deformado del Centro de Costa Rica se continúa con el del Norte y Este de Panamá, configurando los diversos límites de la microplaca de Panamá, con respecto a las placas circumvecinas (Coco, Caribe y Nazca). Lo anterior señala que los límites de esta microplaca definen zonas anchas de deformación con fallamiento complejo, cuya cinemática es determinada por los eventos de colisión de Darién y del levantamiento del Coco, los cuales han provocado que esta microplaca, que originalmente era parte de la placa del Caribe, se pueda hoy identificar como una unidad tectónica independiente con límites propios.

\section{AGRADECIMIENTOS}

Esta investigación se realizó como parte de las actividades del proyecto de investigación 11390-071 “Análisis geoestructural comparado de Cos- ta Rica”. Se agradece a Sergio Rojas su contribución en la confección de las figuras. Igualmente, a Carlos Redondo la selección de los datos sismológicos de la RSN usados en la investigación.

\section{NOTA}

Durante la impresión de este artículo salió publicado en TECTONICS 19 (3): 468-492 (JUNIO-2000) el artículo de Marshall, Fisher \& Gardner titulado: Central Costa Rica deformed belt: kinematics of diffuse faulting across the western Panama block.

\section{REFERENCIAS}

ADAMEK, S., FROHLICH, C. \& PENNINGTON, 1988: Seismicity of the CaribbeanNazca boundary: Constrains in microplate tectonics of the Panama region. - J. Geophys. Res. 93: 2053-2075.

AGUILAR, A., 1984: Sismicidad del 3 al 9 de setiembre de 1980 y su relación con la geología en la cabecera del río Navarro, Cartago. - 160 págs. Univ. de Costa Rica [tesis Lic.].

ALVARADO, G., 1989a: Consideraciones neotectónicas recientes en los alrededores de la laguna de Arenal, Costa Rica. - Bol. Obs. Vulc. Arenal, 3: 6-21.

ALVARADO, G.E., 1989b: Los volcanes de Costa Rica. - 175 págs. EUNED, San José.

ALVARADO, G. E., MORALES, L. D., MONTERO, W., CLIMENT, A. \& ROJAS, W., 1988: Aspectos sismológicos y morfotectónicos en el extremo occidental de la Cordillera Volcánica Central de Costa Rica. - Rev. Geol. Amér. Central, 9: 75-98.

ARIAS, O. \& DENYER, P., 1991a: Aspectos neotectónicos y geológicos de Puriscal y alrededores, Costa Rica. - Rev. Geol. Amér. Central, 12: 83-95. 
ARIAS, O., \& DENYER, P., 1991b: Estructura geológica de la región comprendida en las hojas topográficas Abra, Caraigres, Candelaria y Río Grande, Costa Rica. - Rev. Geol. Amér. Central, 12: 61-74.

ASTORGA, A., FERNANDEZ, J. A., BARBOZA, G., CAMPOS, L., OBANDO, J., AGUILAR, A., \& OBANDO, L. G., 1991: Cuencas sedimentarias de Costa Rica: Evolución geodinámica y potencial de hidrocarburos. Rev. Geol. Amer. Central, 13: 25-60.

BARBOZA, G., BARRIENTOS, J. \& ASTORGA, A., 1995: Tectonic evolution and sequence stratigraphy of the Central Pacific Margin of Costa Rica. - Rev. Geol. Amér. Central, 18: 43-64.

BARQUERO, R. \& ALVARADO, G. E., 1989: Los enjambres de temblores en el arco volcánico de Costa Rica. - Bol. Obs. Vulc. Arenal, 2(4): 18-39.

BARQUERO, R., LESAGE, Ph. METAXIAN, J. P., CREUSOT, A. \& FERNANDEZ, M., 1995: La crisis sísmica en el volcán Irazú en 1991 (Costa Rica). - Rev. Geol. Amér. Central, 18: 5-18.

BARQUERO, R., ROJAS, W., CLIMENT, A. \& MONTERO, W., 1991: El temblor del 9 de agosto de 1991 (Costa Rica). - 14 págs. ICE, San José [Informe interno].

BAUMGARTNER, P. \& MORA, C., 1984: Mapa geológico de Quepos, Puntarenas. - escala 1: 25 000, Instituto Geográfico Nacional, San José.

BORGIA, A., BURR, J., MONTERO, W., MORALES, L. D. \& ALVARADO, G, 1990: Fault propagation folds induced by gravitational failure and slumping of the Costa Rica Volcanic Range: Implications for large terrestrial and Martian edifices. - J. Geophy. Res. 95: 14357-14382.
BOSCHINI, I. M., 1989: Incidencia de las fuentes sísmicas en la región caribe de Costa $\mathrm{Ri}$ ca. - 97 págs. Univ. Costa Rica [tesis Lic.]

BOSCHINI, I., ALVARADO, G., \& ROJAS, W., 1988: El terremoto de Buenavista de Pérez Zeledón (Julio 3, 1983): Evidencia de una fuente sismogénica intraplaca desconocida en Costa Rica. - Rev. Geol. Amér. Central, 8: 111-121.

BOWIN, C. O., 1976: The Caribbean: gravity field and plate tectonics. - Spec. Pap. Geol. Soc. Am. Bull. 169, 79 págs.

CASE, J. E. \& HOLCOMBE, T. L., 1980: Geologic-tectonic map of the Caribbean. - escala 1:250 0000, U. S. Geol. Surv. Miscellaneous Inv., Mapa I-1100.

COLLINS, L. S., COATES, A. G., JACKSON, J. B. C. \& OBANDO, J., 1995: Timing and Rates of Emergence of the Limon and Bocas del Toro Basins: Caribbean effects of Cocos Ridge subduction. - En MANN, P. (ed.) : Geologic and tectonic development of the Caribbean Plate Boundary in Southern Central America. - Geol. Soc. Amer. Spec. Pap. 295: 263-290.

CORRIGAN, J., MANN, P. \& INGLE, J. C., 1990: Forearc response to subduction of the Cocos ridge, Panama-Costa Rica. - Geol. Soc. Amer. Bull. 102: 628-652.

COWAN, H., MACHETTE, M. N., HALLER, K. M. \& DART, R. L., 1998: Map and database of Quaternary faults and folds in Panama and its offshore regions. - 41 págs + mapa escala 1: 750 000, Open-File Report 98-779, U. S. Geological Survey, Boulder.

DENYER, P., 1998: Historic-prehistoric earthquakes, seismic hazards, and Tertiary and Quaternary geology of the Gandoca-Manzanillo National Wildlife Refuge, Limón, Costa Rica. - Rev. Biol. Trop. 6: 237-250. 
DENYER, P., ARIAS, O. \& PERSONIUS, S., 1994: Efecto tectónico del terremoto. - Rev. Geol. Amér. Central, Vol. espec. Terremoto de Limón: 39-52.

\section{DZIEWONSKI, A. M., EKSTROM, G., WOOD-} HOUSE, J. H. \& ZWART, G., 1990: Centroid-moment tensor solutions for JanuaryMarch, 1989. - Phys. Earth Planet. Inter. 59: 233-242.

FAN, G., BECK, S. \& WALLACE, T., 1993: The seismic source parameters of the 1991 Costa Rica aftershock sequence: Evidence for a transcurrent plate boundary. - J. Geophys. Res. 98: 15759-15778.

FERnÁndeZ, J. A., AGUILAR, A., ARRIETA, T., ASTORGA, A., BARBOZA, G., BARRIENTOS, J., BARBOZA, X., BOTAZZI, G., BUSTOS, I., CALVO, C., CAMPOS, L., ESCALANTE, G., LAURITO, C., OBANDO, J., PIZARRO, D., ROJAS, J. F., TEJERA, R., VALERIN, E. \& VALERIO, A., 1997: Mapa geológico de Costa Rica. - escala 1: 750 000, Ministerio del Ambiente y Energía y Refinadora Costarricense de Petróleo,.

FERNÁNDEZ, J. A., BOTAZZI, G., BARBOZA, G. \& ASTORGA, A., 1994: Tectónica y estratigrafía de Baja Talamanca y su relación con el Caribe. - Rev. Geol. Amér. Central, Vol. espec. Terremoto de Limón: 39-52.

FERNÁNDEZ, M., 1995: Análisis sísmico en la parte central de Costa Rica y evaluación del hipotético sistema de falla transcurrente de Costa Rica. - 85 págs. Inst. Geofísica, Universidad Nacional Autónoma de México [tésis MSc.].

FERNÁNDEZ, M., 1996: Evaluación del hipotético sistema de falla transcurrente este-oeste de Costa Rica. - Rev. Geol. Amér. Central, 19/20: 57-74.
FERNÁNDEZ, M., MORA, M. \& BARQUERO, R., 1998: Los procesos sísmicos en el volcán Irazú. - Rev. Geol. Amér. Central 21: 47-59.

FERNÁNDEZ, M., \& PACHECO, J., 1998: Sismotectónica de la región central de Costa Rica. - Rev. Geol. Amér. Central, 21: 5-23.

FISCHER, R., 1980: Recent tectonic movements of the Costa Rican Pacific coast. - Tectonophysics, 70: T25-T33.

FISHER, D. M., GARDNER, T. W., MARSHALL, J., \& MONTERO, W., 1994: Kinematics associated with the late Cenozoic deformation in Central Costa Rica: Western boundary of the Panama microplate. - Geology, 22: 263-266.

FISHER, D. M., GARDNER, T. W., MARSHALL, J., SAK, P. B. \& PROTTI, M. 1998: Effect of subducting sea-floor roughness on fore-arc kinematics, Pacific coast, Costa Rica. - Geology, 26: 467-470.

GARDNER, T. H., VERDONCK, D., PINTER, N. M., SLINGERLAND, FURLONG, K. P., BULLARD, T.H. \& WELLS, S. G., 1992: Quaternary uplift astride the aseismic Cocos Ridge, Pacific coast, Costa Rica. - Geol. Soc. Amer. Bull. 104: 219-232.

GEOMATRIX CONSULTANTS, 1994: Informe final Acueducto de Orosi. Sub-Estudio de la vulnerabilidad sísmica de la conducción: El Llano a Tres Ríos, provincia de Cartago, Costa Rica. - 75 págs. + 16 tablas +47 figuras +10 fotografías +4 apéndices. GEOMATRIX CONSULTANTS.

GOES, S., VELASCO, A., SCHWARTZ, S., \& LAY, T., 1993: The April 22, 1991, Valle de la Estrella, Costa Rica $(\mathrm{Mw}=7,7)$ earthquake and its tectonic implications: A broadband study. - J. Geophys. Res. 98: 8127-8142. 
GÜENDEL, F., 1986: Seismotectonics of Costa Rica: An analytical view of the southern terminus of the Middle America trench. - 104 págs. University of California at Santa Cruz [tesis $\mathrm{PhD}$.].

GÜENDEL, F., 1993: Secuencia sísmica de El Alto del Aguacate Febrero Marzo de 1989. Catálogo de Temblores 1989, Instituto de Investigación Observatorio Vulcanológico y Sismológico de Costa Rica, Universidad Nacional: 155-161.

GÜENDEL, F., MONTERO, C., GONZALEZ, V., SEGURA, J., \& BRENES, J., 1992: Actividad sísmica de caracter superficial registrada por la red sismográfica del OVSICORI-UNA en la hoja San José 1:200.000 entre abril 1984-julio 1988. - Rev. Geogr. Amér. Central, 25/26: 11-44.

GÜENDEL, F., MONTERO, C., ROJAS, D., BRENES, J., SEGURA, J., SAENZ, R. \& GONZALEZ, V., 1993a: Informe sobre el enjambre sísmico ocurrido cerca de la ciudad de Orotina entre el 21 y el 24 de enero de 1989. - Catálogo de Temblores 1989, Instituto de Investigación Observatorio Vulcanológico y Sismológico de Costa Rica, Universidad Nacional, 147-152.

GÜENDEL, A., SEGURA, J., MONTERO, C., GONZALEZ,V., ROJAS, D., BRENES, J., MATA, A., BARQUERO, J., BARRANTES, O., BARBOZA, V., FERNÁNDEZ, E., RODRIGUEZ, H., SAENZ, R., DUARTE, E., \& MARINO, T., 1990: Informe Preliminar Secuencia Sísmica de Puriscal 26 de Marzo, 11 de Julio 1990. - 21 págs + 12 figuras +4 apéndices, Observatorio Vulcanológico y Sismológico de Costa Rica, Universidad Nacional, Heredia.

GÜENDEL, F. \& PACHECO, J., 1992: The 1990-1991 seismic sequence across central Costa Rica: evidence for the existence of a micro-plate boundary connecting the Panama deformed belt and the Middle America
Trench [abs.]. - EOS, Transactions American Geophysical Union, 73: 399.

JACOB, K., PACHECO, J. \& SANTANA, G., 1991: Seismology and tectonics, en Costa Rica Earthquake of April 22, 1991: Reconnaissance report. - Earthquake Spectra, Supplement B, 7: 15-33.

JORDAN, T. H., 1975: The present-day motions of the Caribbean plate. - J. Geophys. Res. 80: 4433-4439.

KESEL, R. H., 1985: Alluvial fan systems in a wet-tropical environment, Costa Rica, - Nat. Geog. Res. 1: 450-469.

KOLARSKY, R., MANN, P., \& MONTERO, W., 1995: Forearc deformation related to the subduction of the Cocos ridge, southeastern Costa Rica. - En: MANN. P. (ed.):Geologic and tectonic development of the Caribbean plate boundary in Southern Central America:. - Geol. Soc. Amer. Spec. Pap. 295: 235-262.

LÓPEZ, A., 1999: Neo-and paleostress partitioning in the SW corner of the Caribbean plate and its fault reactivation potential. - 294 págs., Tübinger Geowissenschaftliche Arbeiten, Reihe A(53).

MADRIGAL, R., 1970: Geología del mapa básico Barranca, Costa Rica. - 59 págs. Min. Energía, Industria y Comercio Informe técnico IX (37), San José.

MANN, P. \& KOLARSKY, R., 1995: East Panama deformed belt: structure, age, and neotectonic significance. - En: MANN. P. (ed.): Geologic and tectonic development of the Caribbean plate boundary in Southern Central America: - Geol. Soc. Amer. Spec. Pap. 295: 111-130.

MATUMOTO, T., \& LATHAM, G., 1976: Results from the Arenal Seismic Network. - 33 págs. ICE, San José [Informe interno]. 
MIYAMURA, S., 1975: Recent crustal movements in Costa Rica disclosed by relevelling surveys. - Tectonophysics, 29: 191-198.

MONTERO, W., 1990: Deformación neotectónica en el centro-sur de Costa Rica. Modelo de origen. - Resúmenes VI Congreso Geológico de América Central 19-23 de noviembre de 1990, San José, Costa Rica, conf. 63.

MONTERO, W., 1994a: Neotectonics and related stress distribution in a subduction-collisional zone: Costa Rica. - En: Seyfried, H. (ed.): Geology of an evolving island arc: southeastern Central America. - Profil, 7: 125-141.

MONTERO, W., 1994b: Sismicidad y neotectónica. - En: Denyer, P. y Kussmaul, S. (eds.): Atlas geológico Gran Area Metropolitana: 147-160. - Ed. Tecnológica de Costa Rica:.

MONTERO, W., 1999: El terremoto del 4 de marzo de 1924. Un temblor interplaca relacionado al límite oeste de la microplaca de Panamá?. Rev. Geol. Amér. Central, 22: 25-62.

MONTERO, W., \& ALVARADO, G., 1995: El terremoto de Patillos del 30 de diciembre de $1952(\mathrm{Ms}=5,9)$ y el contexto neotectónico de la región del volcán Irazú, Costa Rica. Rev. Geol. Amér. Central, 18: 25-42.

MONTERO, W., BARQUERO, R., PERALDO, G., CLIMENT, A., MORA, S., CERVANTES, F., \& PERAZZO, E., 1993: El terremoto de Pejibaye de Turrialba del 10 de julio de 1993: Aspectos sismológicos, neotectónicos y geotécnicos. - 33 págs. ICE [Informe interno].

MONTERO, W. \& BOSCHINI, I., 1991: Interpretación sismotectónica de la región del Golfo de Nicoya. - En: La Crisis Sísmica del Golfo de Nicoya y eventos sísmicos relacionados, Costa Rica, 1990.- ICE, San José [informe interno]: 34-44.
MONTERO, W., DENYER, P., BARQUERO, R., ALVARADO, G. E., COWAN, H., MACHETTE, M. N., HALLER, K. M. \& DART, R. L., 1998: Map and database of Quaternary faults and folds in Costa Rica and its offshore regions. - 63 págs. + mapa escala 1: 500 000, Open-File Report 98-481, U. S. Geological Survey, Boulder.

MONTERO, W. \& DEWEY, J. W., 1982: Shallow-focus seismicity, composite focal mechanism, and tectonics of the Valle Central, Costa Rica. - Seism. Soc. Am. Bull. 71: 1611-1626.

MONTERO, W. \& MIYAMURA, S., 1981: Distribución de intensidades y estimación de los parámetros focales de los terremotos de Cartago de 1910, Costa Rica, América Central. - Rev. Inst. Geogr. Nacional, 2: 9-34.

MONTERO, W. \& MORALES, L. D., 1984: Sismotectónica y niveles de actividad de microtemblores en el suroeste del Valle Central, Costa Rica. - Rev. Geof., Inst. Panam. Geogr. Hist. 21: 21-41.

MONTERO, W. \& MORALES, L. D., 1990: Deformación y esfuerzos neotectónicos en Costa Rica. - Rev. Geol. Amér. Central 11: 69-87.

MONTERO, W., PARDO, M., PONCE, L., ROJAS, W., \& FERNÁNDEZ, M., 1994: Evento Principal y réplicas importantes del terremoto de Limón. - Rev. Geol. Amer. Central, Vol. espec. Terremoto de Limón: 93-102.

MONTERO, W., ROJAS, W., BOSCHINI, I., BARQUERO, R., \& FLORES, H., 1991b: Neotectónica de la región de Puriscal. Origen de la sismicidad de mayo-diciembre de 1990. - Memorias 51 Seminario Nacional de Geotécnia - Ier Encuentro Centroamericano de Geotecnistas, 4.38-4.51. 
MONTERO, W., SALAZAR, L. G. \& MACIAS, J., 1995: Estudio geológico integral del distrito de Guácimo. - 141 págs. +1 V. de anexos, Univ de Costa Rica, San José [Informe interno].

PENNINGTON, 1981: Subduction of the eastern Panama basin and seismotectonics of North Western South America. - J. Geopys. Res. 86: 10753-10770.

PERALDO, G. \& MONTERO, W., 1994: Terremotos coloniales de Costa Rica. - 162 págs, Editorial Tecnológica de Costa Rica, Cartago.

PONCE, L., PARDO, M., DOMINGUEZ, J., MONTERO, W., ROJAS, W., BOSCHINI, I., SUAREZ, G. \& CAMACHO, E., 1994: Estudio de réplicas del terremoto de Limón usando datos locales: Resultados e implicaciones tectónicas. - Rev. Geol. Amér. Central, Vol. espec. Terremoto de Limón: 103-110.

PROTTI, M., GÜENDEL, F.\& MC NALLY, K., 1995a: Correlation between the age of the subducting Cocos plate and the geometry of the Wadati-Benioff zone under Nicaragua-Costa Rica. - En: Paul Mann (ed.): Geologic and tectonic development of the Caribbean plate boundary in Southern Central America:. Geol. Soc. Amer Special Paper 295: 309-326..

PROTTI, M., MC NALLY, K., PACHECO, J., GONZÁlEZ, V., MONTERO, C., SEGURA, J., BRENES, J., BARBOZA, V., MALAVASSI, E., GÜENDEL, F., SIMILA, G., ROJAS, D., VELASCO, A., MATA, A. \& SCHILLINGER, W., 1995b: The March 25, 1990 (MW = 7.0 ML = 6.8), earthquake at the entrance of the Nicoya Gulf, Costa Rica: Its prior activity, foreshocks, aftershocks, and triggered seismicity. - J. Geophys. Res. 100: 20345-20358.

SANDOVAL, L. F, SÁENZ, R., ACUÑA, J., CASTRO, J. F., GÓMEZ, M., LÓPEZ, A., MEDEROS, B., MONGE, A., VARGAS, J., FERNÁNDEZ, T., ULATE, R. \& RAMÍREZ,
C., 1982: Mapa geológico de Costa Rica [9 hojas]. - escala 1:200 000, Instituto Geográfico Nacional, San José.

SAK, P., FISHER, D., GARDNER, T. W., PROTTI, M., \& MARSHALL, J., 1997: Recent landscape evolution and fault kinematics related to basement-exposed blocks, Pacific coast, Costa Rica. - Geol. Soc.Am. Abstracts with programs: A 442.

SHEEHAN, C. A., PENFIELD, G. T., \& MORALES, E., 1990: Costa Rica geologic basins lure wildcatters. - Oil and Gas Jour., April 30: 73-79.

SILVER, E. A., GALEWSKY, J., \& MC INTOSH, K. D., 1995: Variation in structure, style, and driving mechanism of adjoining segments of the North Panama deformed belt. - En: MANN. P. (ed.): Geologic and tectonic development of the Caribbean plate boundary in Southern Central America:. Geol. Soc. Amer. Spec. Pap. 295: 225-233.

SILVER, E. A., REED, D. L., TAGUDIN, E. \& HEIL, D. J., 1990: Implications of the north and south Panama thrust belts for the origin of the Panama orocline. - Tectonics, 9: 261-281.

SOULAS, J. P., 1989: Tectónica activa. Informe de Misión de Consultoría P. H. Siquirres.ICE [informe interno].

SUÁREZ, G., PARDO, M., DOMINGUEZ, J., PONCE, L., MONTERO, W., BOSCHINI, I. \& ROJAS, W., 1995: The Limón, Costa Rica earthquake of 22 April, 1991 ( $\mathrm{Mw}=7.7)$ : Evidence of back-arc thrusting and collisional tectonics in a subduction environment. Tectonics, 14: 518-530.

VERGARA, A., 1988: Tectonic patterns of the Panama block deduced from seismicity, gravitational data and earthquake mechanisms: Implications to the seismic hazard. - Tectonophysics, 154: 253-267. 
VON HUENE, R., BIALAS, J., EMEIS, K., FLUH, E., LEANDRO, C., CROPP, B., CSERNOK, T., FABEL, E., PEREZ. I., FLORES, A., HOFFMANN, J., HOLLER, P., LEON, R., BARRIOS, O., CHAVARRIA, J., JESCHKE, G., \& ESCOBEDO, D., 1995: Morphotectonic features of the Costa Rican Pacific margin surveyed during the Sonne 76 cruise. - En: MANN. P. (ed.): Geologic and tectonic development of the Caribbean plate boundary in Southern Central America:. Geol. Soc. Amer. Spec. Pap. 295: 291-307.

WELLS, S., BULLARD, T., MENGES, C., DRAKE, P., KARAS, K., KELSON, K., RITTER, J. \& WESLING, J., 1988: Regional variations in tectonic geomorphology along a segmented convergent plate boundary, Pacific coast of Costa Rica. - Geomorphology, 1: 239-265.

WOLTERS, B., 1986: Seismicity and tectonics on southern Central America and adjacent regions with special attention to the surroundings of Panama. - Tectonophysics, 128: 21-46.

WOODWARD-CLYDE, 1993: A preliminary evaluation of earthquake and volcanic hazards significant to the major population centers of the Valle Central, Costa Rica. - 89 págs.Final Report prepared for Ret Corporation [informe interno]. 